Universidade de Brasília

Faculdade de Economia, Administração, Contabilidade e Ciências da Informação e Documentação

\author{
DEPARTAMENTO DE ADMINISTRAÇÃO
}

TRABALHO DE CONCLUSÃO DE CURSO

\title{
MOBILE MARKETING: A aceitabilidade dos usuários brasileiros ao marketing via Bluetooth
}

\section{Luccas Victor Rodrigues Ruzzon}


Universidade de Brasília

Faculdade de Economia, Administração, Contabilidade e Ciências da Informação e Documentação

DEPARTAMENTO DE ADMINISTRAÇÃO

TRABALHO DE CONCLUSÃO DE CURSO

\title{
MOBILE MARKETING: A aceitabilidade dos usuários brasileiros ao marketing via Bluetooth
}

\author{
Luccas Victor Rodrigues Ruzzon
}

Professor Orientador:

\section{Prof. Guilherme Augusto Castelo Branco Arruda}

"Trabalho apresentado em cumprimento às exigências acadêmicas parciais da disciplina Estágio Supervisionado em administração para a obtenção do grau de Administrador"

Brasília - DF

Junho / 2009 
RUZZON, Luccas Victor Rodrigues.

Mobile Marketing: A aceitabilidade dos usuários brasileiros ao marketing via Bluetooth

Monografia - Universidade de Brasília, Departamento de Administração, 2009.

Orientador: Prof. Guilherme Augusto Castelo Branco Arruda.

1. Marketing. 2. Mobile marketing. 3. Tecnologia. 
Universidade de Brasília

Faculdade de Economia, Administração, Contabilidade e Ciências da Informação e Documentação

DEPARTAMENTO DE ADMINISTRAÇÃO

MOBILE MARKETING: A aceitabilidade dos usuários brasileiros ao marketing via Bluetooth

A Comissão Examinadora, abaixo identificada, aprova o Trabalho de Conclusão do Curso de Administração da Universidade de Brasília do aluno

\section{Luccas Victor Rodrigues Ruzzon}

Guilherme Augusto C. Branco Arruda, Prof.

Professor-Orientador

Domingos Sávio Spezia, Prof.

Professor-Examinador

Brasília, 15 de junho de 2009. 
A meus pais e irmãos, aos meus avôs, e a Júlia. 
Agradeço a meus pais que proporcionaram minha educação e são os responsáveis por aonde cheguei. A meus irmãos que sempre estão ao meu lado e são mais que grandes amigos. Aos amigos que fiz na universidade, que com certeza farão muita falta. A Júlia que me apoiou em todos os momentos e que espero poder contar sempre, além de ser minha motivação. Obrigado a todos. 
"O homem é um ser móvel."

Siqueira (2004). 


\section{RESUMO}

Os avanços tecnológicos permitem uma discussão relevante voltada para o marketing em um cenário de novas tecnologias de comunicação. O mobile marketing é uma ferramenta bastante nova de relacionamento com os consumidores. O presente trabalho tem como objetivo verificar a aceitabilidade dos usuários de celular brasileiros ao mobile marketing, em especial através da tecnologia Bluetooth. A respeito da metodologia optou-se pelo levantamento quantitativo descritivo com base em fontes primárias, levantadas através de livros, artigos na área de marketing e órgãos do setor de telecomunicações, além de fontes secundárias. Realizou-se uma entrevista onde foram aplicados 300 questionários a usuários de celular residentes em Brasília e São Paulo. O marketing via Bluetooth tem boa receptividade entre os entrevistados, principalmente entre os jovens, pois possuem maior familiaridade com essa tecnologia. Comparado com o envio de propagandas no celular somente, seja através de qualquer meio, o marketing via Bluetooth mostrou também maior aceitabilidade. No entanto, percebe-se que os consumidores desejam escolher quais conteúdos irão receber como publicidade no celular e a freqüência. Dessa maneira, obter a permissão dos consumidores para o envio de mensagens publicitárias é fundamental para a efetividade da campanha. O Bluetooth então se mostra uma alternativa interessante para o mobile marketing, devido a seu baixo custo e boa aceitação pelos consumidores.
1. Mobile marketing
2. Telecomunicações
3. Comportamento do Consumidor 


\section{SUMÁRIO}

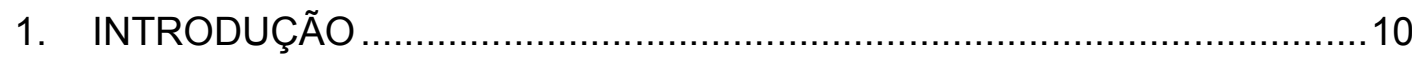

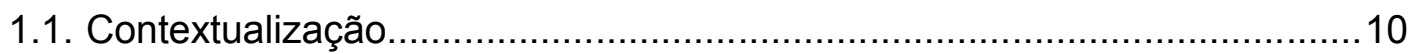

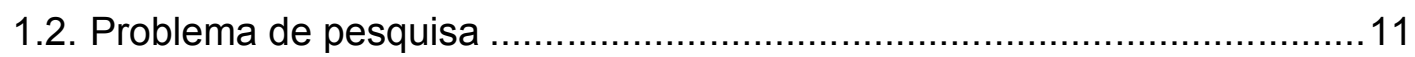

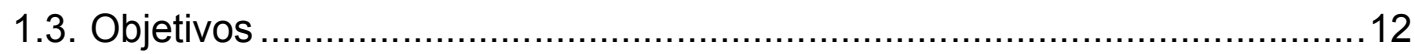

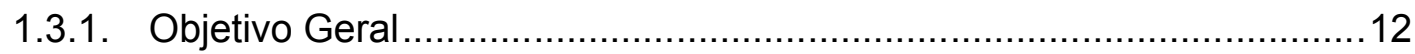

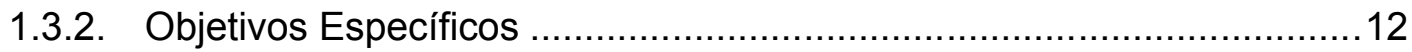

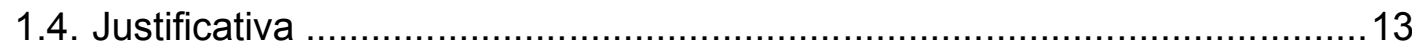

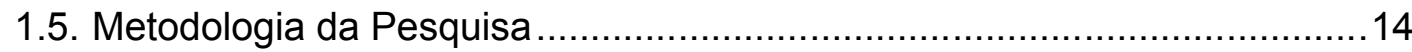

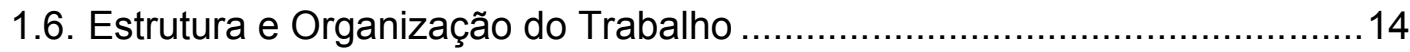

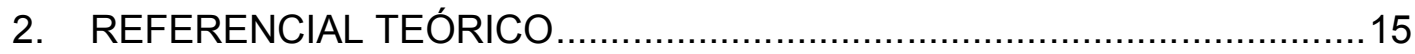

2.1. Conceito e aplicação do Mobile Marketing .............................................15

2.1.1. Características do Mobile Marketing.................................................16

2.1.2. Tipos de campanhas e aplicações........................................................19

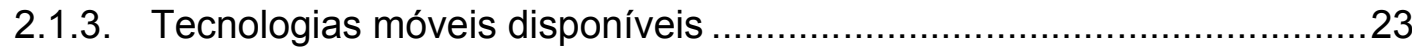

2.2. O Bluetooth nas campanhas de Mobile Marketing .....................................24

2.3. Mobile Marketing no Brasil ..................................................................26

2.4. Do marketing tradicional ao novo marketing ...........................................29

2.4.1. Comportamento do consumidor wireless.............................................. 31

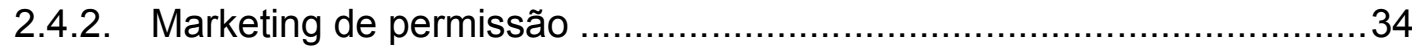

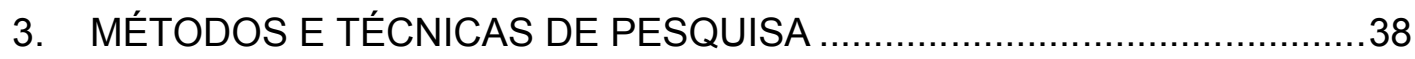

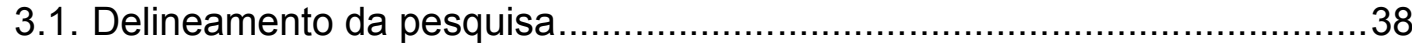

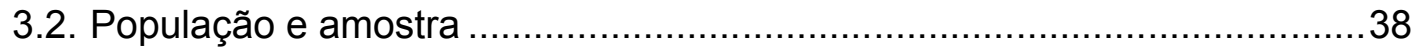

3.3. Procedimentos de coleta e de análise de dados .......................................40

4. APRESENTAÇÃO E ANÁLISE DOS RESULTADOS DA PESQUISA ........41

4.1. Perfil demográfico dos entrevistados ........................................................ 41

4.2. Comportamento quanto ao uso do celular pelos entrevistados ..................42

4.3. A aceitabilidade dos entrevistados ao marketing via Bluetooth ..................47

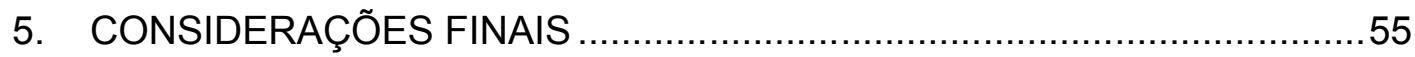

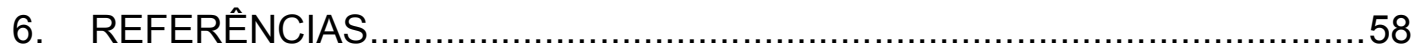

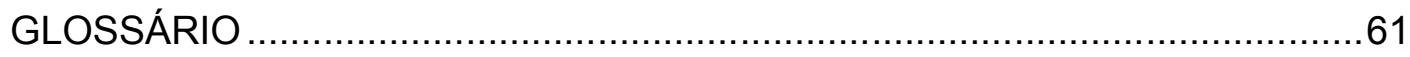

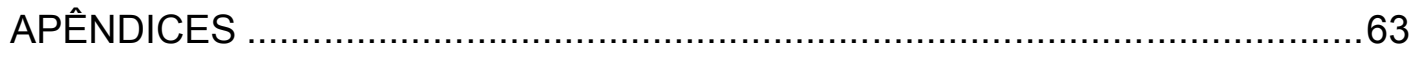




\section{LISTA DE ILUSTRAÇÕES}

Figura 1 - Funcionamento de uma campanha de mobile marketing ......................22

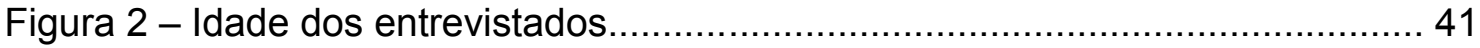

Figura 3 - Período de uso de celular pelos entrevistados................................42

Figura 4 - Conhecimento sobre a tecnologia Bluetooth..................................47

Figura 5 - Desejo de receber propagandas pelo celular............................... 48

Figura 6 - Meios preferidos para publicidade no celular................................ 50

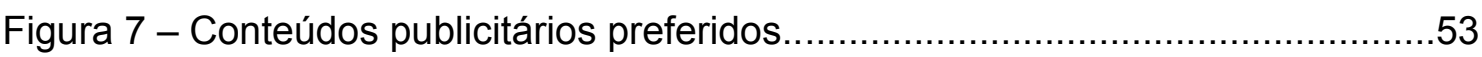

Figura 8 - Solicitação para ativar o Bluetooth em um centro comercial...................54 


\section{LISTA DE TABELAS}

Tabela 1 - Características gerais da comunicação móvel atual...............................19

Tabela 2 - Importância dos recursos do celular no momento da compra de um aparelho novo e faixa etária

Tabela 3 - Freqüência de uso dos recursos SMS, WAP e Bluetooth e faixa etária..46

Tabela 4 - Freqüência de uso dos recursos SMS, WAP e Bluetooth e sexo.............46

Tabela 5 - Conhecimento sobre a tecnologia Bluetooth e faixa etária.......................47

Tabela 6 - Aceitabilidade as propagandas pelo telefone por faixa etária...................49

Tabela 7 - Aceitabilidade as propagandas pelo telefone por formação.....................49

Tabela 8- Meios preferidos para publicidade por faixa etária....................................51

Tabela 9 - Aceitabilidade as propagandas pelo telefone celular e os meios preferidos para receber publicidade no celular......................................................52

Tabela 10 - Solicitação para ativar o Bluetooth em um centro comercial..................54 


\section{INTRODUÇÃO}

\subsection{Contextualização}

O celular além de ser um meio de comunicação muito forte e com público-alvo definido, possui capacidade de ampliação e é um dos eletrônicos mais difundidos no Brasil. A partir de todas as facilidades e vantagens proporcionadas pelos avanços da tecnologia sem fio, o uso do telefone móvel como estratégia de marketing passou a ser considerado como uma poderosa ferramenta. Isso porque o aparelho está muito tempo com seu usuário e em todos os lugares. Devido ao seu tamanho, Sultan e Rohm (2006), começaram a tratar o celular como a "marca na palma da mão". Com essas características e mobilidade, os consumidores podem ser atingidos pelo marketing em qualquer lugar e em qualquer hora.

Segundo a ANATEL - Agência Nacional de Telecomunicações - o Brasil terminou fevereiro de 2009 com 152,4 milhões de celulares e atingiu uma densidade de 79,94 cel./100 hab. Com crescimento acumulado em 2009 de 1,42\% e de média de $26 \%$ de crescimento nos últimos 5 anos. No mundo, segundo pesquisa UIT, Wireless Intelligence e GSA/Informa, em julho de 2008 eram mais de 3,66 bilhões de celulares, com densidade de 55 cel./100 hab. Além do extraordinário crescimento da telefonia móvel, o celular tornou-se um dos objetos mais pessoais dos usuários, que acreditam poderem estar conectados 24 horas por dia através do aparelho.

Segundo os web sites Mobilepedia e Webinsider empresas como McDonald's, Coca-Cola, Volvo, Nike e Adidas já exploram o celular como nova mídia. São muitas as formas promocionais que estão sendo utilizadas envolvendo o celular, internet $\mathrm{e}$ mídia tradicional. A facilidade de interação que o celular trouxe mudou sobremaneira - comportamento das pessoas, proporcionando uma mudança na vida do consumidor. Esse estudo busca analisar qual a receptividade dos consumidores brasileiros a essa nova forma de comunicação e venda das organizações e refletir sobre o atual cenário do país quanto a essa nova estratégia mercadológica.

A falta de estudos profundos e a atualidade do tema tornam esse trabalho um desafio e uma oportunidade, uma vez que o mercado se torna mais competitivo a cada dia e os consumidores exigem das organizações ferramentas e soluções personalizadas a suas necessidades. 
Além disso, são motivadores para o estudo do mobile marketing a relevância da telefonia móvel no crescimento da economia brasileira, as mudanças comportamentais dos consumidores e os avanços tecnológicos que proporcionam cada vez mais serviços com qualidade e recursos aos usuários.

\subsection{Problema de pesquisa}

Ao observar as campanhas de marketing a partir da perspectiva do consumidor, a eficácia dos meios de comunicação é um desafio. $\mathrm{O}$ crescente número de meios e mídias torna cada vez mais difícil conseguir a atenção dos consumidores. Na era da informação, foi dado poder aos consumidores que agora tem acesso ininterrupto e imediato a informação, modificando seu comportamento de compra. Esse novo perfil torna cada vez mais difícil atingir bons resultados com as estratégias de comunicação tradicionais. Nesse cenário o uso do mobile marketing como estratégia de comunicação é um novo desafio.

Os novos meios digitais criaram poderosas ferramentas para o marketing direto e interativo. No entanto, as estratégias de comunicação tradicionais do marketing são baseadas em uma lógica de ininterrupção (GODIN, 2000), onde os consumidores são forçados a momentaneamente prestar atenção à mensagem. Nesse contexto surge o marketing de permissão, uma nova abordagem na comunicação do marketing. Segundo Marinova, Murphy e Massey, 2002, as organizações obtêm benefícios ao terem permissão dos consumidores para serem contatados. Essa permissão - mesmo não sendo uma garantia de que os consumidores irão prestar atenção a mensagem e sim apenas uma indicação de áreas de potencial interesse resolveria as dificuldades de acesso ao consumidor.

As estratégias de mobile marketing dependem diretamente da permissão dos usuários para receberem mensagens e participarem das campanhas de marketing. É fundamental então entender qual a percepção e receptividade do consumidor a esse novo tipo de comunicação de marketing.

A MMA - Mobile Marketing Association - realizou em 2008 uma extensa pesquisa na América Latina focada no perfil dos usuários de telefone celular. O resultado mostrou o Brasil como um forte mercado para o desenvolvimento do marketing utilizando a plataforma móvel: dos brasileiros entrevistados, $74 \%$ mostraram 
interesse alto ou moderado em receber esse tipo de publicidade. Quanto ao perfil dos usuários, o recurso mais valorizado na hora de adquirir um aparelho celular é a câmera fotográfica seguida pela tecnologia Bluetooth.

Essa procura dos usuários brasileiros pela conectividade Bluetooth surpreendeu e de certa forma indica um caminho para atingir os consumidores no país. Segundo Terence Reis, diretor gerente da MMA para a América Latina, até o momento não se sabia se esse tipo de ação era bem vinda e o mercado deve passar a olhar com mais atenção para campanhas que envolvam esse tipo de tecnologia.

Nesse sentido, tem-se como questão central (problema de pesquisa) desse estudo: Qual a aceitabilidade dos usuários de celular brasileiros a campanhas de mobile marketing através da tecnologia Bluetooth?

\subsection{Objetivos}

Para que o problema de pesquisa possa ser respondido serão apresentados a seguir os objetivos deste trabalho. Primeiro destaca-se o objetivo geral e em seguida são apresentados as hipóteses que poderão resultar este trabalho.

\subsubsection{Objetivo Geral}

O objetivo geral desse trabalho é identificar e analisar a aceitabilidade dos usuários de telefonia móvel brasileiros quanto a campanhas de mobile marketing que utilizam como recurso a tecnologia Bluetooth.

\subsubsection{Objetivos Específicos}

- Verificar as principais aplicações do mobile marketing e tecnologias utilizadas pelas organizações que fazem uso desse tipo de mídia.

- Identificar o impacto de fatores demográficos como idade, gênero, ocupação, etc. na aceitabilidade dos consumidores ao mobile marketing em campanhas via Bluetooth. 
- Identificar os principais usos e aplicações dos usuários de telefonia móvel brasileiros quanto ao aparelho celular e suas funcionalidades.

- Avaliar qual a familiaridade dos usuários brasileiros a tecnologia Bluetooth.

- $\quad$ Caracterizar o comportamento dos consumidores quanto a ações de mobile marketing via Bluetooth.

\subsection{Justificativa}

Segundo a MMA, os investimentos em publicidade pelo celular irão alcançar US\$ 55 bilhões até 2011. Cada vez mais é preciso se conscientizar a respeito do crescimento desse mercado. Apesar de ainda pouco explorado, muitos profissionais da área de marketing acreditam ser o celular a grande mídia do futuro.

Ainda que no Brasil, o mercado esteja começando agora a se movimentar no intuito de explorar essa nova mídia, na Europa e Japão, por exemplo, o mobile marketing conta com diversas empresas especializadas e operadoras preparadas para atender a demanda desde 2001.

Além disso, por ser uma modalidade de marketing relativamente recente, os estudos e aplicações em desenvolvimento são iniciais e escassos, principalmente no Brasil. O desenvolvimento de trabalhos no meio acadêmico nesta área é então fundamental para consolidar os conceitos e práticas do mobile marketing.

É importante também que os profissionais de marketing tenham acesso a informações que possibilitem o uso do celular como ferramenta de marketing. É ainda razão para a escolha do tema o conhecimento que este trabalho pode produzir para o mercado de telefonia celular, empresas, consumidores e profissionais, uma vez que buscará identificar a receptividade dos usuários a esse novo tipo de mídia, em especial com uso da tecnologia Bluetooth. A importância dada a esse tipo de recurso nos aparelhos celulares pelos usuários aliado a falta de estudos específicos sobre o tema, custo elevado de campanhas via SMS e tímida participação no Brasil no uso de mensagens de texto em relação a outros países são grandes motivadores 
também para este trabalho. O Bluetooth pode ser então uma alternativa importante e até agora pouco estudada para o mobile marketing.

Além disso, também foi importante na escolha do tema a vivência profissional do pesquisador no segmento de telefonia móvel.

\subsection{Metodologia da Pesquisa}

Este trabalho envolveu dois métodos de pesquisa: a exploratória e a descritiva. Valendo-se de pesquisa bibliográfica a fim de aumentar a compreensão do autor sobre o tema e propiciar subsídios para a pesquisa de campo e análise de resultados.

A pesquisa de campo utilizou o método descritivo quantitativo de pesquisa, sendo realizado um levantamento para conseguir informações sobre determinada população. A pesquisa se deu a partir da coleta de dados obtidos por meio de um questionário estruturado e não disfarçado, elaborado pelo autor desse trabalho.

\subsection{Estrutura e Organização do Trabalho}

Este trabalho foi dividido em cinco capítulos. O primeiro refere-se à introdução e o segundo, à revisão bibliográfica sobre o tema. O terceiro capítulo contém a metodologia da pesquisa. O quarto refere-se à discussão dos resultados e o quinto corresponde às conclusões do estudo. Por fim tem-se a bibliografia e apêndices. 


\section{REFERENCIAL TEÓRICO}

\subsection{Conceito e aplicação do Mobile Marketing}

A MMA - uma organização que mantém o interesse em agregar valores ao desenvolvimento sustentável do mobile marketing - define o mobile marketing como toda ação de marketing, propaganda ou promoção de vendas que utilize um canal de comunicação "móvel". Ainda segundo essa associação a mídia móvel permite que as empresas divulguem suas propagandas ou demais assuntos através de marketing direto e buscando novas maneiras de interação com seus clientes.

Segundo Lucia Lucena (2009), a mobilidade é uma ferramenta para as ações de marketing e os equipamentos móveis ou também chamados sem fios - wireless em inglês - são à base das ações de marketing quanto ao mobile marketing ou mobile marketing.

O celular é dessa maneira o equipamento mais utilizado na aplicação de estratégias de mobile marketing atualmente. $\mathrm{O}$ aparelho, além de um objeto de uso pessoal e portátil - o que leva uma personalização única possibilitando uma comunicação com alcance diferenciado - introduziu o conceito de mobilidade no qual se pode manter contato com qualquer um a qualquer hora e em qualquer lugar.

A popularização do celular o levou ao topo da lista dos produtos de tecnologia em todas as faixas etárias e classes sociais, deixando de ser um equipamento de luxo para ter adoção quase que universal. Além disso, nota-se que deixou de ser utilizado apenas para fazer e receber ligações e ganhou papel no entretenimento e lazer dos usuários.

Para Román, González-Menezes; Marinas (2007) o aparelho celular é a ferramenta de marketing com maior potencial de futuro, uma vez que se torna um dos mais eficazes meios de comunicação direta e interativa entre empresa e consumidor.

O modo como o celular rapidamente se disseminou na sociedade mudou o comportamento das pessoas. O fato do aparelho estar sempre junto ao seu dono leva as empresas a utilizarem este meio para manter relações consistentes, uma vez que os obstáculos relacionados a conseguir encontrar seu cliente ou ter que ligar várias vezes pra seu telefone fixo diminuíram. 
Atualmente as funções mais usadas nos celulares dos norte-americanos são: voz, SMS, alertas, calculadora, fotografia. E as funções mais desejadas pelos consumidores americanos no futuro são: alertas de viagens, pagamento de estacionamento, ofertas especiais e comunicações de marketing, ingressos para jogos de temporadas, cartões de crédito e débito (Michael e Salter 2006). Huelsen (2009) define os motivos para o uso do mobile marketing como:

"Em um mundo cuja atenção dos consumidores está diluída pelo excesso de informação e saturada pelo bombardeio das mídias de massa, o marketing móvel representa uma alternativa para atrair a atenção do consumidor. Os dispositivos móveis vistos como mídia são um eficiente meio para falar com público de forma segmentada e até certo ponto individualizada."

O mobile marketing é dessa maneira um instrumento único com potencial reconhecidamente importante como ferramenta de marketing. A evolução tecnológica certamente é base das evoluções nesse serviço para permitir maior aproveitamento dos veículos de comunicação para divulgação de temas focados no público-alvo de cada organização.

\subsubsection{Características do Mobile Marketing}

O surgimento de novas tecnologias e a necessidade das organizações expandirem suas ações de comunicação para consumidores cada vez mais exigentes resulta em estudos crescentes na área de mobile marketing. Facchetti et al., (2005 apud Kotler et al, 2002) refere-se à mobile marketing como "qualquer forma paga de apresentação impessoal e promoção de bens, serviços, idéias por uma empresa identificada" usando equipamentos wireless, como o meio de comunicação.

O alcance dos consumidores através de equipamentos móveis em qualquer lugar e momento em tempo real a principal característica do mobile marketing segundo Lucena (2009). Torras; Albuquerque (2005) referem-se à interatividade em tempo real como característica do mobile marketing. Além disso, existe possibilidade de superar barreiras de localização até então inalcançadas.

Sultan e Rohm (2005) defendem que o mobile marketing, unir alta interatividade com os consumidores independentemente de localização comparado às mídias tradicionais. $\mathrm{Na} \mathrm{TV}$, jornais, revistas, o consumidor não estabelece contato em 
tempo real com a empresa. Já através dos aparelhos celulares o envio e recebimento de mensagens são simultâneos.

Além disso, os custos de publicidade utilizando o mobile marketing são menores quando comparado a ferramentas de marketing tradicionais. Segundo Lucena (2009):

\begin{abstract}
"As propagandas enviadas pelas empresas podem variar de informações sobre lançamentos de serviços e produtos, até informar ao usuário que ele está a alguns metros de uma loja dessa empresa e que naquele dia há uma promoção para ele caso apresente a referida mensagem recebida em seu aparelho no momento da compra."
\end{abstract}

Além de ter como uma de suas principais vantagens ser a forma mais barata de comunicação direta com usuários finais, os celulares ajudam ainda a aumentar a eficiência das organizações, seja no uso corporativo, melhorando a comunicação entre colaboradores e organização, como na Gestão de Relacionamento com o Cliente (CRM), aumentando a qualidade dos serviços ao cliente.

Conforme Haig (2002) as seguintes características tornam atraente essa nova mídia móvel:

- Custo - As campanhas de mobile marketing tendem a ter melhor custobenefício quando comparada a outros tipos de mídia devido ao baixo custo de transmissão de dados, em especial o SMS.

- Imediaticidade - Os celulares têm capacidade de escrita de mensagens para respostas imediatas.

- Privacidade - Mesmo quando recebidos em lugar público, os dados enviados via celular se mantêm privados.

- Conveniência - É possível o envio de mensagens a qualquer lugar e qualquer hora a qualquer pessoa.

- Ubiqüidade - Devido à difusão de celulares pelo mundo e a quantidade de aparelhos pode-se chegar a qualquer tipo de perfil ou consumidor. 
- Interação - o nível de interação ente empresa e consumidores é alto e o contato é direto sem intermediários.

- Integração - o celular pode ser usado como novo meio de comunicação com consumidores reforçando campanhas com mídias tradicionais.

Outra vantagem importante é a possibilidade do marketing viral com a utilização de campanhas via celular. Róman; González-Mesones e Marinas (2007) citam também a mensurabilidade dos resultados e a alta taxa de penetração como características do mobile marketing.

Além disso, o ganho de agilidade nas campanhas de comunicação e marketing seja por parte do consumidor que recebe e envia mensagens com facilidade e rapidez, sem perda de tempo, tanto para a empresa que elabora os materiais de forma muito mais simples e ágil possibilita benefícios a todos os envolvidos. As pessoas têm cada vez menos tempo para ler jornais ou ver televisão, assim, o celular possibilita o acesso à informação de forma rápida e sem grandes esforços.

No entanto, a MMA defende que a utilização do mobile marketing é uma ferramenta a ser utilizada de forma integrada com outros elementos tradicionais e que esse é um fator chave para o sucesso. Segundo Lucena (2009) o mobile marketing proporciona "novas e diferentes maneiras de comunicação e campanhas, dependendo dos objetivos da iniciativa específica". Dessa maneira o mobile marketing é mais eficaz quando integrado a outros canais de comunicação. 


\begin{tabular}{|c|c|c|c|c|}
\hline $\begin{array}{c}\text { Forma de } \\
\text { comunicação }\end{array}$ & $\begin{array}{l}\text { Linguagem } \\
\text { escrita }\end{array}$ & Imagens & Público & Uso \\
\hline \multirow{4}{*}{$\begin{array}{l}\text { - Oral } \\
\text {-Texto e imagens } \\
\text { - Vídeos }\end{array}$} & $\begin{array}{l}\text { - Linguagem } \\
\text { direta em WAP - } \\
\text { Sites }\end{array}$ & $\begin{array}{l}\text { - Fotos e vídeos } \\
\text { com baixa } \\
\text { definição }\end{array}$ & $\begin{array}{l}\text { - Alta taxa de } \\
\text { penetração na } \\
\text { população }\end{array}$ & $\begin{array}{l}\text { - Possibilidade de } \\
\text { ações interativas: } \\
\text { web }\end{array}$ \\
\hline & $\begin{array}{l}\text { - Mensagens de } \\
\text { texto }\end{array}$ & & & \\
\hline & $\begin{array}{l}\text { - Uso de } \\
\text { abreviaturas, sem } \\
\text { uso de acentos e } \\
\text { pontuação } \\
\text { reduzida para } \\
\text { mensagens SMS }\end{array}$ & $\begin{array}{l}\text { - Variam de } \\
\text { aparelho para } \\
\text { aparelho em } \\
\text { tamanho de } \\
\text { exibição e } \\
\text { qualidade de som }\end{array}$ & $\begin{array}{l}\text { - Possibilidade de } \\
\text { segmentar } \\
\text { detalhadamente }\end{array}$ & $\begin{array}{l}\text { - Possibilidade de } \\
\text { ações passivas: } \\
\text { recebimento de } \\
\text { mensagens }\end{array}$ \\
\hline & & $\begin{array}{l}\text { - Tempo para } \\
\text { baixar o conteúdo } \\
\text { é ainda grande. }\end{array}$ & $\begin{array}{l}\text { - Impacto } \\
\text { individual }\end{array}$ & $\begin{array}{l}\text { - Possibilidade de } \\
\text { ações } \\
\text { programáveis: } \\
\text { avisos de } \\
\text { serviços }\end{array}$ \\
\hline
\end{tabular}

Tabela 1 - Características gerais da comunicação móvel atual.

Fonte: Adaptado de Huelsen, 2009, p. 178.

\subsubsection{Tipos de campanhas e aplicações}

Novas tecnologias surgem a cada dia, os fabricantes de celulares investem em aparelhos com telas maiores e softwares mais avançados e as operadoras se dedicam cada vez mais em disponibilizar pacotes de dados mais acessíveis. Dessa maneira serviços diferenciados, como vídeos e sons se tornam viáveis. O mobile marketing possibilita diversas oportunidades, sejam para o envio de mensagens com conteúdo sobre promoções ou serviços quanto para oferecer conteúdo de entretenimento como imagens e vídeos.

Para Huelsen (2009) os principais tipos de ações de marketing que o mobile marketing possibilita quanto ao mix de comunicação são:

- Marketing direto - Mensagens como comunicação direta com consumidores.

- Promoção - Ações de incentivo a venda de produtos e serviços.

- Propaganda - Anúncios e patrocínios de conteúdo viam web pelo celular.

O envio de mensagens SMS é a tecnologia utilizada para as ações de marketing direto. Seu objetivo pode ser informar, divulgar ou promover produtos e serviços. Além do baixo custo seu retorno é alto, em especial quando direcionada a base de 
clientes disposta a receber mensagens de determinados produtos e serviços. Esse tipo de base de clientes é a chamada base opt-in segmentada. Godin (2000) afirma que opt-in consiste em dar a permissão para uma empresa enviar algum tipo de comunicação.

Torras; Albuquerque (2005) afirmam que as campanhas que utilizam o mobile marketing funcionam conforme o tripé abaixo:

- Base de dados opt-in - lista com celulares e perfil do target que autorizou o recebimento.

- Servidores de envio e processamento de mensagens recebidas computadores conectados às operadoras de celular para processar o envio, recebimento e análise das mensagens.

- Celulares - aparelhos do target habilitados para receber mensagens.

Para Huelsen (2009) são necessários, no entanto alguns cuidados na realização de ações de marketing direto pelo celular. É preciso direcionar as mensagens a segmentos de consumidores específicos a fim de melhorar o retorno da ação. Devese também respeitar o consumidor e utilizar com parcimônia essa ferramenta além de oferecer ao cliente a possibilidade de não receber mais esse tipo de mensagem. O uso de linguagem correta ao tipo de mídia e público é fundamental. E por fim deve-se aproveitar ao máximo a oportunidade de mensuração dos resultados para aperfeiçoar a campanha.

Segundo Haig (2002) as campanhas de mobile marketing utilizam atualmente basicamente quatro tipos de tecnologias para entregar dados:

- SMS - Serviço de mensagens curtas de texto. É a ferramenta mais utilizada para comunicação, uma vez que está presente em quase todos os celulares.

- WAP - Protocolo de internet móvel. Permite a criação de portais móveis e veiculação de banners e links publicitários.

- Bluetooth - Tecnologia que permite o estabelecimento de conexão e troca de dados entre dois ou mais aparelhos eletrônicos sem o uso de fios. 
- Voz e tecnologias emergentes como jogos multimídias, aplicativos em JAVA (linguagem de programação), tecnologia 3G, etc.

As empresas hoje, para desenvolver uma campanha de mobile marketing, devem procuras agências de publicidade especializadas e operadoras de telefonia e agências que desenvolvam conteúdo. Além disso, devem se preocupar também com a relevância de suas mensagens. $O$ cuidado em selecionar e direcionar tudo que for enviado é essencial, isso porque os clientes não estão interessados em receber conteúdo que não lhe interessa a qualquer momento.

Assim, entender as necessidades dos clientes e obter permissão para contatá-lo é essencial na construção de um relacionamento duradouro e evitar reclamações. Para Lucena (2009), no mobile marketing a permissão é um fator chave "já que a legislação atual exige a autorização do destinatário para poder enviar mensagens de texto e imagens".

Torras; Albuquerque (2005) e Román; Gonzáles-Mesones e Marinas (2007) citam os seguintes tipos de campanhas de mobile marketing principais:

- Campanhas pull - O usuário precisa enviar uma mensagem, normalmente SMS, para participar da promoção ou para ganhar algum prêmio. São sempre integradas a outros tipos de mídia como televisão, rádio ou impressas.

- Campanhas push - Nesse tipo de campanha a empresa envia para um banco de dados opt-in um SMS ou MMS com conteúdo informativo ou formal. Em um banco de dados opt-in estão cadastrados pessoas que autorizaram o envio de mensagens promocionais.

- Campanhas de diálogo continuo ou de múltiplas etapas - Nesse tipo de campanha existe um dialogo continuo entre empresa e usuário, gerando muita informação permitindo uma segmentação efetiva de público.

Haig (2002) e Bayne (2002) analisaram alguns tipos de campanhas planejadas com objetivo específico. As principais são: 
- Competições - O usuário deve enviar uma mensagem de texto para um determinado número contendo um código ou palavra que está na embalagem ou exposto em outras mídias para concorrer a prêmios, sorteios e incentivos.

- Downloads - Os usuários têm acesso a jogos, sons e imagens de maneira patrocinada ou mediante aceitação para futuras campanhas.

- Ofertas especiais - São campanhas com objetivo de atrair o público até a loja oferecendo promoções, através de utilização de CRM ou banco de dados

- Notícias e "Alerts" - Os usuários têm acesso a notícias de forma patrocinada pelas empresas que buscam construir relacionamentos e ofertar produtos.

- Jogos - Jogos interativos onde o usuário e empresa se comunicam com objetivos específicos. Outra maneira é ofertar jogos patrocinados aos consumidores para fidelização.

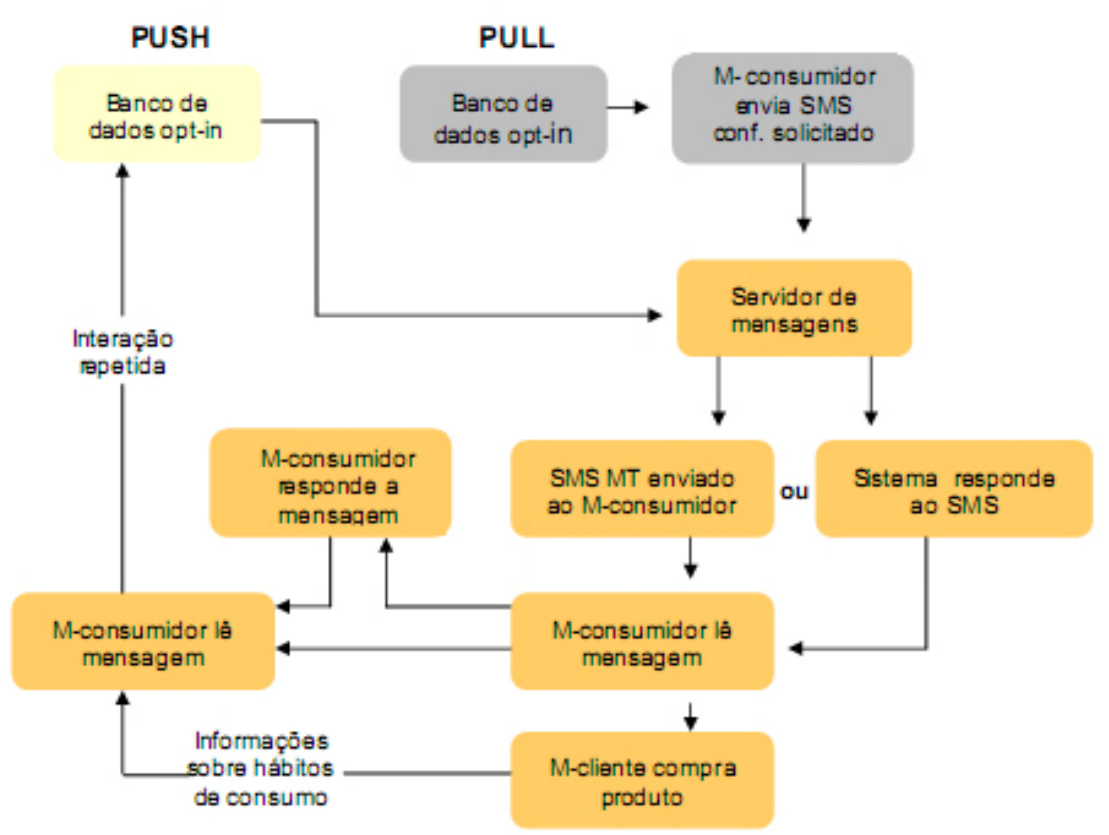

Figura 1 - Funcionamento de uma campanha de mobile marketing.

Fonte: Adaptado de Torras; Albuquerque (2005, p.36). 


\subsubsection{Tecnologias móveis disponíveis}

É fundamental para o melhor aproveitamento do mobile marketing, conhecer e entender todo o funcionamento dessa nova ferramenta. Isso inclui não só os equipamentos, tecnologias e ferramentas de comunicação, mas também quais as organizações são responsáveis pelo cenário móvel.

Os celulares ainda são os equipamentos wireless (sem fios) mais utilizados principalmente devido seu preço acessível. São exemplos de conexões wireless: Infra-Red (radiação infravermelha para equipamentos sem fios), Wi-Fi e Wi-Max (tecnologias que utilizam faixas de freqüência para acesso em fio) e Bluetooth (padrão que utiliza ondas de rádio para curtas distancia).

A maioria dos aparelhos celulares possui diversos recursos básicos como recepção e envio de mensagens de texto, identificador de chamadas, caixa postal, entre outros. As duas tecnologias mais utilizadas pelas operadoras são GSM e CDMA e segundo o web site Tecnomundo a vantagem da tecnologia GSM é a utilização de chips que impossibilitam a clonagem da linha telefônica.

Cada vez mais os aparelhos se tornam diferenciados, com designs inovadores e funções como câmera fotográfica digital, tocadores de música e rádio FM. Além de inúmeras funções inovadoras que levaram a criação de smartphones - celulares com funções avançadas como conexão via Wi-Fi e Bluetooth, sincronização com computador pessoal, softwares avançados, entre outras características - os avanços da indústria de telecomunicações levaram a tecnologias de dados rápidas.

A tecnologia de acesso móvel 3G, em estágio inicial no Brasil, possibilita o trafego de voz, dados e vídeo em alta velocidade e garante melhores serviços para transmissão de voz, textos e dados.

Existem também tecnologias como a Wi-Fi e Wi-Max que são tecnologias de interconexão entre dispositivos sem fio através de faixas de freqüência. Atualmente muitos locais públicos como cafés, universidades e aeroportos disponibilizam a seus usuários acesso a internet via Wi-Fi.

O uso de ferramentas de comunicação wireless depende de tecnologias que viabilizam o uso do celular como ferramenta de marketing e comunicação. Entre elas estão: 
- WAP - Sigla para Protocolo de Aplicação Wireless em português. É a internet sem fio via celular.

- Bluetooth - Uma tecnologia de baixo custo para comunicação sem fio entre dispositivos eletrônicos. Muitos celulares utilizam esse recurso para comunicação com computadores pessoais e troca de arquivos entre usuários.

- Tecnologias JAVA e BREW - são linguagens de programação muito utilizadas para o desenvolvimento e execução de aplicativos para dispositivos móveis.

As ferramentas de comunicação mais utilizadas no mobile marketing são:

- SMS (Short Message Service) - Sigla para Serviço de Mensagem Curta em português. Possibilita a emissão de mensagens de texto entre dispositivos.

- MMS (Multimedia Messaging Service) - Sigla para Serviço de Mensagem Multimídia em português. Possibilita o envio de fotos e vídeos entre dispositivos.

- Mobile vídeo - Através dessa ferramenta é possível assistir a TV e vídeos no equipamento móvel.

- Mobile Advertising - Da mesma forma como nos aparelhos de TV é possível assistir propagandas no aparelho sem fio.

\subsection{O Bluetooth nas campanhas de Mobile Marketing}

A tecnologia Bluetooth permite uma comunicação rápida, simples, segura e barata entre telefones celulares, smartphones, computadores, periféricos, fones de ouvido e outros dispositivos, utilizando ondas de rádio ao invés de cabos. Desse modo podese fazer com que dois equipamentos troquem informações através da simples aproximação entre eles. O web site Mobilepedia define a tecnologia Bluetooth como: 
"Um protocolo de comunicação que permite que os dispositivos móveis equipados com um chip especial recebam e enviem informações sem fio, com um curto alcance, na faixa de freqüência de $2.4 \mathrm{GHz} . "$

O site da Ericsson, empresa de soluções em telecomunicações, defende que a tecnologia sem fio Bluetooth torna possível transmitir sinais por curtas distancias entre telefones, computadores e outros dispositivos, simplificando dessa maneira a comunicação e sincronismo entre dispositivos, sendo um padrão global que:

- Elimina os fios e cabos entre os equipamentos.

- Alem da possibilidade de redes especificas oferece máximo sincronismo entre todos seus dispositivos pessoais.

- Torna mais fácil a comunicação tanto de dados como voz.

Para a ABI Research, os celulares hoje representam 60\% do mercado de Bluetooth do mundo - 1,2 bilhão de unidades em 2008, com previsão de dobrar até 2013. A ANATEL divulgou que em 2008, 56\% dos celulares homologados contavam com a tecnologia. Segundo o site Mobilepedia, em 2008 houve um aumento muito grande nas ações de marketing através do Bluetooth e a previsão de um aumento ainda maior em 2009 e anos seguintes.

Várias grandes empresas já utilizam essa ferramenta como mais um recurso de marketing. A Coca-Cola já conta com algumas experiências no pais. Em uma ação para promover seu filme "Fabrica de Felicidade" a empresa utilizou de vários recursos do móbile marketing, entre eles o Bluetooth. As pessoas que visitavam o stand da empresa no Morumbi Shopping em São Paulo recebiam o convite para ativar seu Bluetooth e receber no celular um vídeo promocional do filme. Segundo dados divulgados pela MMA 59\% dos aparelhos encontrados pelo equipamento de divulgação aceitaram receber o vídeo.

Outro exemplo de ação da Coca-Cola aconteceu no Shopping Center Recife, um dos maiores da America Latina. Segundo o site Mobilepedia, as pessoas que passavam pelo estande da empresa eram convidadas a ativar o Bluetooth e receber conteúdos exclusivos no seu celular como imagens, músicas e vídeos. 


\subsection{Mobile Marketing no Brasil}

No Brasil, a partir da abertura do mercado de telecomunicações em 1998 o interesse de inúmeras empresas aumentou drasticamente. O país é hoje um dos mercados com maior potencial para avanço da tecnologia móvel e demais tecnologias de telecomunicações. Segundo a Anatel o Brasil é hoje o quinto maior mercado de telefonia móvel do mundo, atrás apenas da Rússia, Índia, Estados Unidos e China. Com mais de 150 milhões de celulares, a maioria deles pré-pagos, são 80,90\% contra $19 \%$ pós-pagos segundo a Teleco (2008). Esse tipo de plano proporciona um controle dos usuários sobre seus gastos, mas ao mesmo tempo inibem acesso a planos de dados que possibilitam o acesso a internet via celular.

No Brasil, o crescimento do mercado é explicado pela alta densidade. Segundo a Anatel, o país atingiu em 2009 uma densidade de 79,94 cel./100 hab.. Ainda segundo a Agência o Distrito Federal é o estado líder em densidade com um índice de 109,76, ou seja, 1,09 aparelhos celulares para cada habitante. Em segundo lugar fica o Rio de Janeiro com índice de 72,09, seguido pelo Rio Grande do Sul, com 71,95 .

Para a Teleco, esse dinamismo o setor se deve aos seguintes fatores:

- Grande oferta de aparelhos celulares com desenhos sofisticados e baixo custo.

- Atratividade tecnológica que está sendo oferecida aos usuários, por se tratar de um mercado dinâmico que oferece novos produtos e serviços.

- Aceitação por parte dos clientes que utilizam e gostam de tecnologia moderna e interativa. Com isso, a grande concorrência neste mercado e as mudanças ocorridas no setor fazem com que as operadoras de telefonia móvel busquem se adaptar constantemente a esta realidade tecnológica, acompanhando a evolução internacional, oferecendo os mesmos recursos para o mercado brasileiro.

No país, os serviços de dados respondem a somente a uma pequena parcela - de 4 a 7\% - das receitas das operadoras, enquanto os serviços de voz são os responsáveis pela grande fatia de receita (CESAR, 2006). Esse cenário, no entanto 
está em mudança, já que as operadoras estão investindo nos mercados corporativos e jovens, propensos a aceitar novas tecnologias e novos serviços com maior rapidez. Existe também uma intensificação na comunicação de marketing dos serviços de valor agregado, tais como o SMS, MMS e o vídeo on demand, que demonstra o interesse das operadoras em aumentar o consumo de dados dos assinantes. Cada vez mais o Brasil se consolida como mercado promissor e alvo de investimentos de grandes grupos internacionais, seguindo tendência mundial de fusões, aquisições e parcerias.

Apesar do grande número de aparelhos celulares e do crescimento constante do número de usuários no país, os equipamentos tecnologicamente falando são mais simples quando comparados a europeus, asiáticos e americanos. Dessa maneira, as campanhas ainda se encontram limitadas às mensagens de texto, na maioria dos casos. Certos tipos de campanhas com utilização de vídeos e imagens são ainda restritos e a maioria das campanhas é baseada em promoções pelo celular que substituem os antigos cupons e cartas.

Observam-se algumas ações promocionais isoladas no uso de poucas mensagens de divulgação e ações publicitárias limitadas a patrocínio de mensagens SMS. Para Huelsen (2009), os principais entraves no uso do celular como mídia no Brasil são:

- Operadoras funcionam como único canal de acesso a seus clientes. Elas detêm informações sobre a base de assinantes e podem limitar o tipo de conteúdo oferecido e vendido.

- Falta de conhecimento sobre tecnologias e possibilidade de uso por parte das empresas e consumidores.

- Os modelos de negócio estão em formação, assim se desconhecem os tipos de remuneração entre agências, empresas de mídia, operadoras e integradoras.

- Falta de regulamentação e de boas práticas de mercado.

Segundo Lucena (2009) o maior desafio no país não é o desenvolvimento de tecnologias e sim atender os consumidores brasileiros, tendo em vista a grande diferença entre as classes sociais e os altos custos para distribuir as tecnologias 
existentes. É preciso mostrar também ao público que o celular não é somente um dispositivo para fazer e receber chamadas, mas também um equipamento que pode Ihe auxiliar em muitas outras tarefas, como efetuar pagamentos e ter acesso a entretenimento.

Para Mort e Drenan (2005, apud PURA, 2003) os serviços móveis, ou M-Services em inglês, são qualquer tipo de serviço que pode ser acessado através de um equipamento móvel e em que haja interação entre empresa e consumidor. Sua principal vantagem é a personalização do serviço. Para isso as organizações devem conhecer profundamente seus clientes para lhes trazerem benefícios reais.

No Brasil, bancos, restaurantes, táxis e outras prestadoras de serviços já oferecem serviços de pagamento através de celular em algumas cidades. No chamado $M$ payment (Mobile-payment ou pagamento móvel) o cliente envia, por exemplo, um SMS para a central do sistema informando o nome do estabelecimento e o preço juntamente com uma senha pré-determinada. O estabelecimento então recebe uma mensagem confirmando o pagamento. Existem outras formas de pagamento oferecidas pelas operadoras e bancos. No cinema, por exemplo, o chamado M-ticket (Mobile-ticket ou ticket móvel) o consumidor pode utilizar o celular como bilhete para entrada no cinema.

Quanto às mensagens SMS, no país, seu envio como ferramenta de marketing é quase exclusividade das operadoras. Com exceções de algumas promoções e programas de TV, como o Big Brother, que vêm utilizando esse meio de acesso para interagir com os usuários. No entanto, comparando com o que se vê na Europa em termos mercadológicos isso ainda é incipiente no Brasil.

A Mobile Marketing Association, instaurada na América Latina em 2008, realizou nesse ano uma pesquisa entre internautas do Brasil, México e Argentina, sendo o primeiro estudo focado no perfil dos usuários de celulares do continente. A pesquisa apontou a região como um mercado forte para o desenvolvimento da comunicação entre marcas e consumidores utilizando o mobile marketing.

O Brasil, conforme a pesquisa está bastante receptivo ao mobile marketing, uma vez que $34 \%$ das pessoas mostraram alto interesse em receber esse tipo de publicidade e $40 \%$ mostraram interesse moderado. $72 \%$ dos entrevistados se disseram 
dispostos a integrarem as listas de permissão das operadoras (opt-in). 17\% ainda disseram já terem tido algum contato com o mobile marketing.

A pesquisa ainda mostrou que os tipos de publicidade desejados pelos entrevistados são em primeiro lugar o recebimento de mensagens com alertas de ofertas, mensagens com ações de relacionamento pós-compra, sorteios e mensagens baseadas em serviços de localização. Interessante notar que as formas de publicidade com menos interesses são as votações e anúncios puros, e as votações são hoje uma das formas mais utilizadas no Brasil.

Quanto ao perfil dos brasileiros, o estudo mostrou que o recurso mais valorizado na hora de adquirir um equipamento ainda é a câmera fotográfica embarcada com $89 \%$, seguida pelos fones de ouvido sem fio e tecnologia Bluetooth com 85\%. Para Terence Reis, diretor gerente da MMA para a América Latina, a procura do brasileiro pela conectividade via Bluetooth surpreendeu bastante.

O acesso a internet móvel é dificultado principalmente pelos altos custos de pacotes de dados praticados pelas operadoras. No Brasil $24 \%$ disseram utilizar o recurso, e apenas $6 \%$ o fazem diariamente.

Terence Reis, conclui que o estudo mostrou o Brasil como o país que apresentou melhores perspectivas para o desenvolvimento do canal na América Latina, tanto pelo tamanho do mercado e da receptividade da população as novas tecnologias quanto pelo histórico de investimentos publicitários.

\subsection{Do marketing tradicional ao novo marketing}

Para Kotler (2006) marketing "envolve a identificação e a satisfação das necessidades humanas e sociais" e define ainda de maneira bem simples dizendo que "ele supre necessidades lucrativamente". A Associação Americana de Marketing define o marketing como uma função organizacional e um conjunto de processos que envolvem criação, comunicação, e entrega de valor para os clientes, e ainda a administração do relacionamento com eles. Las Casas (2009) define a administração de marketing como:

"Área do conhecimento que engloba todas as atividades concernentes as relações de troca orientadas para a criação de valor dos consumidores, visando alcançar determinados objetivos 
de empresas e indivíduos através de relacionamentos estáveis e considerando sempre o ambiente de atuação e o impacto que estas relações causam no bem-estar da sociedade".

Antigamente a comercialização dos produtos não se preocupava muito com a forma de comunicação, embalagem e transporte do produto. Atualmente o comércio dos produtos não consiste somente em transferência do produto ao consumidor. Las Casas (2009) defende que o aspecto diferenciador da comercialização moderna é o consumidor como ponto de partida para qualquer negócio. Sendo essa orientação ao cliente o conceito e filosofia que orienta os profissionais de marketing a buscar a satisfação das necessidades e desejos de um determinado público-alvo.

Quanto à evolução da comercialização e da orientação do marketing, existe um consenso entre os principais autores para as seguintes fases: orientação para a produção e produto, vendas, marketing e mercado.

Algumas mudanças recentes estão acontecendo na prática de comercialização. Uma dessas mudanças mais recentes foi a transformação do marketing de massa para o marketing individual. Devido a concorrência crescente, as organizações passaram a fragmentar o mercado de maneira especifica, possibilitando a formação de novos mercados-alvo. Isso possibilitou a formação de nichos de mercado, que são grupos reduzidos de consumidores formados pela associação de várias características.

A evolução das organizações na busca por atingir os consumidores de forma cada vez mais personalizada fez surgir o "marketing um a um", onde cada indivíduo é um foco de atendimento. Dessa maneira, as diferentes necessidades e desejos dos clientes passaram a ser atendidos de maneira customizada pelas empresas. Novos mecanismos foram criados para possibilitar esse contato mais próximo com os consumidores tais como o telemarketing e callcenters e a internet.

Os avanços tecnológicos possibilitaram um maior grau de interatividade entre consumidor e empresa. Através da internet é possível realizar "todo o processo de comercialização na forma digital, adaptando-se as características e utilizando os recursos" (LAS CASAS, 2009). Para Reedy; Schullo e Zimmerman (2000) o marketing eletrônico "são todas as atividades on-line ou eletrônicas que facilitam a 
produção e a comercialização de produtos e serviços para a satisfação dos desejos e necessidades do consumidor".

A ligação de vários dispositivos pela tecnologia wireless tem possibilitado novos caminhos a esse tipo de comercialização. A internet está cada vez mais interligada a outros tipos de mídia e o telefone celular é uma das mais recentes. A convergência da internet com a tecnologia sem fio segundo Las Casas (2009) começa desenvolver uma nova ferramenta que passa a ser chamada de mobile marketing.

\subsubsection{Comportamento do consumidor wireless}

Para Kotler (2006) o campo comportamento do consumidor "estuda como as pessoas, grupos e organizações selecionam, compram, usam e descartam artigos, serviços, idéias ou experiências para satisfazer suas necessidades e desejos".

Os fatores que influenciam as atitudes e comportamento dos consumidores são vários, desde fatores culturais e sociais (amigos, familiares, ocupação e classe social) como demográficos - idade e sexo, por exemplo - e até psicológicos, como suas motivações e desejos.

Enquanto o comportamento diz respeito a como o consumidor age em relação a um produto, as atitudes revelam o que o consumidor pensa sobre algo ou acredita. É comum as atitudes e comportamentos dos consumidores não serem coerentes e muitas vezes o indivíduo pode ter uma atitude muito favorável a um determinado produto, achando ele muito superior aos outros, no entanto no momento da compra opta por outro produto. Para Ramuski (2009) os motivos para a divergência entre comportamento e atitude são os fatores que influenciaram tanto sua atitude quanto sua ação de compra. Enquanto a atitude é formada em razão de uma bem-sucedida construção de imagem da marca, por exemplo, o comportamento pode ter sofrido influencias como a alta do preço do produto ou promoção de outra marca.

Assim, para as empresas é fundamental conhecer como o consumidor se comporta, mesmo sendo difícil ter completo controle sobre isso, uma vez que seu comportamento pode mudar repentinamente no momento da compra por exemplo. Quando falamos do consumidor wireless, existem ainda outros fatores importantes como o fato do meio de comunicação ser novo e diferente daquilo que ele está acostumado e envolver tecnologia manuseada pelo consumidor. 
O consumidor wireless, no entanto não é um novo consumidor, e sim "um consumidor com novas e acuradas exigências em razão da virtualidade da relação mantida com as organizações que se relacionam com ele" (RAMUSKI, 2009).

Para Kotler (2006) a aceitação em maior ou menor grau de um produto depende do atendimento a um conjunto de condições que facilitam seu aceite ou o impactarão. Ramuski (2009) relacionou cada uma dessas condições com o celular:

- Oferta de inovação em relação aos demais produtos existentes - O fato do celular ser um produto wireless e suas inúmeras funções cada vez mais avançadas lhe garante vantagens em relação a qualquer outro tipo de meio de comunicação. O celular é hoje muito mais do que um simples meio de comunicação.

- Compatibilidade com o desejo do cliente - O celular vai de encontro com o que é desejado por seus clientes: mobilidade, interatividade, socialização, entretenimento, etc.

- Baixa complexidade da inovação - Certamente um telefone celular é de fácil utilização. Muito embora essa facilidade seja percebida melhor pelos jovens do que pelos consumidores mais velhos.

- Divisibilidade da inovação - O aparelho celular é um dispositivo simples e suas vantagens facilmente percebidas.

- Comunicação da inovação ao usuário - Comunicar aos usuários potenciais as vantagens do celular e suas funções não é complexo.

- Custo, risco, incerteza, aprovação social - O celular atende a todos esses aspectos. Existem celulares a preços muito acessíveis, o risco é cada vez menor devido a novas tecnologias que impedem a clonagem, a incerteza quanto a seu funcionamento não existe e sua aprovação social é automática, ampla e irrestrita. Muitas vezes inclusive o celular é considerado um produto que confere status. 
O mercado wireless, formado pelo conjunto de consumidores e proprietários em especial de um celular, é composto em sua maioria por jovens. Além disso, são também os jovens que mais utilizam o aparelho como meio de entretenimento e socialização.

Algumas pesquisas já vêm sendo realizadas para compreender melhor o consumidor wireless. Grant e D'onohoe (2007) realizaram junto ao publico denominado "jovem-novo", com idade entre 13 e 19 anos, e puderam identificar as seguintes características: os jovens utilizam o celular porque ele os entretém, representa uma forma de estar com outras pessoas sem que eles precisem sair de casa e é um meio de aprender mais sobre si mesmos e sobre outras pessoas, uma vez que através dele pode-se ganhar tempo para pensar na resposta ou estabelecer argumentos para situações inesperadas, já que escolhem a hora e lugar para ler e responder mensagens. Os jovens também enxergam o celular como um acessório fashion, contribuindo para lhes conferir status.

Quanto ao publico "jovem-maduro", até os 30 anos, o que se percebe é que o conteúdo das mensagens é o principal meio de fidelizá-lo. Meyer (2006) defende que o cliente será mais fiel a um produto, não porque este lhe é ofertado com ênfase ou freqüência maior, e sim porque em nome do produto muita informação relevante de seu interesse lhe é enviada.

Ramuski (2009) como resultado de uma pesquisa conduzida com esse tipo de público na cidade de São Paulo pode concluir que o consumidor "jovem-maduro" brasileiro de celular, em especial os de classes sociais mais altas, não possuem barreiras culturais para operacionalização desse produto, nem de renda para ter os modelos mais avançados e não se apresenta muito diferente do encontrado em outros mercados, especialmente em relação a mensagens promocionais. Ressalta também que é difícil realizar uma avaliação dessa natureza em nosso mercado onde o celular não é ainda utilizado para esse fim com a mesma intensidade que Europa e Estados Unidos por exemplo.

No entanto, segundo a mesma autora, pode-se enumerar alguns aspectos norteadores para aquelas organizações que pretendem fazer um maior uso do celular como ferramenta de marketing:

“... a) respeito pela permissão obtida para acessar os clientes; b) uso ético de suas bases de dados; c) investimento em estudos 
que permitam segmentar o mercado, identificando o conteúdo que efetivamente atraia segmentos de interesse; d) acompanhamento de forma acurada do comportamento e evolução dos consumidores-alvos, permitindo que o conteúdo ofertado aos clientes seja eficaz não só para atração, mas principalmente manutenção desses clientes; e) início de contatos com oferta de conteúdo gratuito; f) desenvolvimento de conteúdo específico para essa mídia, sem transplantes da TV para o celular..."

O celular então como ferramenta de marketing, através de sua inovação tecnológica, propicia sua maior aceitação junto aos consumidores-alvos. O sucesso dessa mídia ocorre por vários motivos e depende, no entanto de uma condição básica: obtenção do consentimento do consumidor para que uma organização o contate. Dessa maneira o uso do celular para divulgação de publicidade deve ser comedida e ética. Motivando assim o consumidor a permitir o acesso das organizações com que eles se relacionam.

Desse modo as organizações precisam realizar análises mais profundas do consumidor a ser atingido e do conteúdo de seu interesse para que o relacionamento entre empresa e cliente progrida otimizando o uso dessa nova e importante ferramenta mercadológica.

\subsubsection{Marketing de permissão}

Godin (2000) a partir da observação de que os consumidores estão cada vez mais com menos tempo para realizar suas tarefas e querem exercer menor esforço para escolher os produtos dos quais necessitam introduziu o conceito de marketing de permissão. Segundo Haig (2002) o termo diz respeito a qualquer atividade de marketing que depende da permissão do consumidor.

Ainda segundo Godin (2000) o marketing de permissão é aquele "que oferece ao consumidor a oportunidade de aceitar voluntariamente o marketing que the querem apresentar" e ainda complementa dizendo que o marketing de permissão "estimula os consumidores a participar de uma campanha de marketing de longo prazo e interativa, em que eles são de alguma forma recompensados por prestar atenção".

O conceito de marketing de permissão é importante para se entender as premissas sobre privacidade e opt-in para utilização não só do SMS como ferramenta de mídia, 
mas também do Bluetooth, por exemplo, uma vez que em ambos os caso é necessário a autorização do usuário para ser contatado.

A permissão dos usuários pode vir de várias maneiras, seja no momento do cadastro do cliente em uma loja, web site, telefone, ou ainda diretamente pelo celular através de uma mensagem de texto ou configuração do aparelho no caso do Bluetooth. Após o consumidor aceitar receber mensagens da empresa essa pode Ihe conhecer melhor e desenvolver produtos e serviços mais adequados a sua necessidade.

Para Godin (2000) ainda o marketing de permissão se relaciona com a confiança, já que não há venda na sua ausência. Dessa maneira então, entende-se que o marketing de permissão pressupõe uma troca de informações entre as partes envolvidas, em um processo de comunicação contínua mais pessoal, onde há liberdade para a interação que se torna benéfica para ambos.

O marketing eletrônico, on-line, e-commerce e o mobile marketing têm modificado as práticas tradicionais de comunicação e informação e com isso vêm se desenvolvendo uma nova cultura. Para Garcia; Barboza (2009) o cliente passa a ter acesso ininterrupto a serviços e produtos e tem o poder de decidir sobre o que a organização deve ou não oferecer. Hoje o cliente tem o poder de permitir ou autorizar aquilo que ele quer ver e comprar com um simples toque no celular ou computador.

Segundo Godin (2000) os consumidores da nova economia criaram "anticorpos" que resistem ao marketing tradicional. Se o consumidor concorda em prestar atenção às mensagens a ele enviadas fica muito mais fácil informá-lo sobre produtos ou serviços. O marketing de permissão tem características próprias que o diferenciam do marketing de interrupção. Segundo Godin (2000), as características do marketing de permissão são:

- Antecipado - As pessoas esperam que o produto seja oferecido a elas.

- Pessoal - Mensagens e contatos são customizados e personalizados.

- Relevante - É necessário que a mensagem ou informação diga algo relevante e que o consumidor esteja interessado. 
- Freqüente - É preciso que o consumidor sinta sempre a presença da marca.

- Mensurável - Mensurar as campanhas fica mais fácil, sendo possível acompanhar a evolução dos clientes e entrada de novos clientes.

- Escolha do target - Tendo a campanha interesse em apenas uma parcela de seus clientes é possível escolher para quem enviar a sua mensagem.

- Escolha do "timing" - É possível escolher quando o cliente será contatado de forma que seja conveniente para ele e em momentos que eles estejam mais suscetíveis à mensagem.

Para Godin (2000), a permissão tem cinco níveis importantes que analisados dentro de um grau de importância de bom para ruim devem ser percebidos e estudados pelo profissional de marketing para que sua ação seja segura e objetiva. Para o autor, o objetivo do marketing de permissão é:

"Levar os consumidores a subir mais um degrau da escada da permissão, fazendo-os passar de estranhos a amigos e depois a clientes. E de clientes a clientes leais. Em cada novo degrau da escala, a confiança se desenvolve, a responsabilidade se fortalece e os lucros crescem."

Existem ainda dois conceitos importantes relacionados ao marketing de permissão: opt-in e opt-out. Enquanto opt-in consiste em dar permissão para uma empresa enviar algum tipo de informação, que pode assumir diversas formas, tais como: formulários na internet, SMS, formulários em lojas e correspondência. O opt-out consiste em oferecer ao cliente a possibilidade de interromper o recebimento da comunicação autorizada previamente. Toda comunicação enviada ao usuário deve conter uma mensagem explicando como ele pode solicitar o cancelamento do envio de mensagens (GODIN, 2000).

É importante ressaltar que o marketing de permissão estabelece regras como não abusar do envio de material, facilitar a saída do sistema de envio e primar por conteúdos especializados que realmente sejam do interesse do consumidor. Dessa maneira, trabalhar essa nova forma de atrair a atenção e a confiança tem estimulado os consumidores a aumentar a permissão às empresas e permite um 
aprofundamento nas relações levando o consumidor eventual a tornar-se um cliente fiel. 


\section{MÉTODOS E TÉCNICAS DE PESQUISA}

\subsection{Delineamento da pesquisa}

O presente trabalho envolveu dois métodos de pesquisa: a exploratória e a descritiva. Em sua fase exploratória valeu-se da pesquisa bibliográfica, mais especificamente do método de levantamento bibliográfico (MATTAR, 1999). O principal objetivo dessa fase foi aumentar a compreensão do autor sobre o tema e propiciar subsídios para a pesquisa de campo e análise dos resultados.

Em uma segunda etapa, foi utilizado o método de pesquisa descritivo quantitativo, já que segundo Malhotra (2001), a pesquisa quantitativa busca aplicar uma análise estatística a partir de dados quantificados, sendo uma pesquisa que tem o objetivo de descrever algo. Roesch (2006) afirma que esse tipo de pesquisa deve ser usando quando se busca obter informações sobre determinada população. Em um levantamento desse tipo observam-se características diversas dos elementos de uma população (BARBETTA, 2002).

Assim, foi realizado um levantamento para conseguir informações sobre determinada população. Nesse tipo de pesquisa o controle sobre os eventos comportamentais não existe e o foco são os acontecimentos contemporâneos.

Uma pesquisa pode ser classificada quanto a seus fins e seus meios (VERGARA, 2007). Quanto a seus fins a pesquisa é classificada como descritiva, uma vez que relata características de certa população e estabelece correlações entre variáveis, definindo sua natureza. Quanto aos meios, é uma pesquisa de campo, ou seja, uma investigação empírica onde acontece um fenômeno ou onde se encontra elementos para explicá-lo (VERGARA, 2007)

Mattar (1999) cita também que nesse tipo de pesquisa, os objetivos são bem definidos e os procedimentos de coleta formais e estruturados para que se possa avaliar as opções de curso de ação ou solucionar problemas.

\subsection{População e amostra}

Os indivíduos da pesquisa são usuários de celular brasileiros de todas as faixas etárias e gênero. 
População é o conjunto dos elementos que pode ser observado e deseja-se abranger no estudo de acordo com as características que se pretende levantar (BARBETTA, 2002). Vergara (2007), define população como o conjunto de elementos que possui características determinadas passiveis de estudo.

Roesch (2006) afirma que usa-se o processo de amostragem quando é necessário extrair uma parte da população em estudo para investigar, uma vez que o total da população inviabiliza o trabalho. Para Malhotra (2001), uma amostra é um subgrupo dos elementos que compõem a população, selecionado para participar do estudo. Vergara (2007) define a amostra como parte do universo escolhida conforme um critério de representatividade. A amostra da pesquisa foi composta por usuários de celular residentes em Brasília e São Paulo, tendo sido caracterizada como nãoprobabilística.

O tipo de amostragem não-probabilística utilizada foi a por conveniência, uma vez que a população não estava disponível para ser sorteada. Ou seja, não se possuía uma listagem dos elementos da população para sorteá-los. Porém, não existe a intenção nesse trabalho de generalizar os resultados encontrados a toda população, e sim conhecer a receptividade ao mobile marketing via Bluetooth de um grupo.

Como na amostragem não probabilística não se exige que se utilize fórmulas para encontrar o tamanho da amostra representativa do universo, a amostra da pesquisa foi de 300 respondentes.

Procurou-se obter o mesmo número de entrevistados da pesquisa realizada em 2008 pela Mobile Marketing Association na América Latina, com um total de 437 respondentes no Brasil. Para isso, o estudo valeu-se de instrumento de pesquisa lançado na internet. Como a rede mundial de computadores é um meio democrático e que possibilita atingir todo tipo de público pode-se conseguir uma amostragem bastante heterogênea.

Dessa maneira, devido às limitações de tempo e recursos característicos de um trabalho acadêmico dessa natureza e dificuldades correlatas, optou-se por conduzir o estudo a partir de uma amostra por conveniência, tendo-se ciência das limitações desse método de amostragem. 


\subsection{Procedimentos de coleta e de análise de dados}

Esta investigação se deu a partir da coleta de dados primários obtidos por meio de um questionário estruturado (com questões elaboradas previamente e seguindo uma seqüência lógica, vide apêndice) e não disfarçado (os entrevistados sabiam que estavam respondendo um questionário) elaborado pelo autor desse trabalho. Um questionário é um conjunto formal de perguntas cujo objetivo é obter informações dos entrevistados (MALHOTRA, 2001)

O questionário foi desenvolvido pelo próprio pesquisador, especialmente para essa pesquisa a partir dos aspectos considerados de importância para os objetivos da análise. O instrumento foi composto por perguntas fechadas e semi-abertas, permitindo que os entrevistados expressassem suas opiniões sobre os quesitos analisados.

Como a proposta do trabalho é coletar informações somente de usuários da telefonia celular, uma questão filtro constou no inicio do questionário. Segundo Malhotra (2001), as questões filtro permitem ao pesquisador uma seleção sobre os entrevistados, assegurando que eles satisfaçam as exigências do perfil em estudo e que possuam informações suficientes sobre o assunto abordado.

O questionário foi respondido pelo próprio entrevistado através da internet, sem que o pesquisador observasse 0 respondente no momento do preenchimento. Foi realizada, no entanto, uma abordagem prévia ao respondente via email ou convite lançado em comunidades virtuais e sites de relacionamento.

Roesch (2006) afirma que os dados coletados em uma pesquisa quantitativa são analisados estatisticamente. A tabulação dos dados foi realizada através do software SPSS, versão 12.0, um programa especializado em recursos estatísticos. A construção dos gráficos foi feita através do software Microsoft Excel.

A análise das questões foi feita através de recursos da estatística descritiva. Sendo as variáveis classificadas como métricas e não-métricas. As variáveis métricas foram analisadas segundo a média e desvio-padrão. As variáveis não-métricas foram analisadas a partir da distribuição de freqüência. 


\section{APRESENTAÇÃO E ANÁLISE DOS RESULTADOS DA PESQUISA}

Serão apresentados aqui os resultados obtidos através do instrumento de coleta de dados, e também a discussão das informações obtidas. A pesquisa, representada por um total de 300 questionários como amostra, foi realizada junto a usuários de celular brasileiros, residentes em Brasília e São Paulo no período de 11 de maio de 2009 a 28 de maio de 2009, sendo 138 respondentes da cidade de São Paulo e 162 de Brasília.

\subsection{Perfil demográfico dos entrevistados}

Vários são os fatores que influenciam as atitudes e comportamento do consumidor. Esses fatores podem ser tanto de origem social e cultural como fruto de suas próprias características, como sexo e idade por exemplo. (RAMUSKI, 2009). Um dos objetivos desse estudo é traçar o perfil demográfico dos entrevistados. Para atingir esse objetivo foi questionada idade (Figura 4.1), sexo, ocupação, grau de escolaridade e renda familiar dos respondentes.

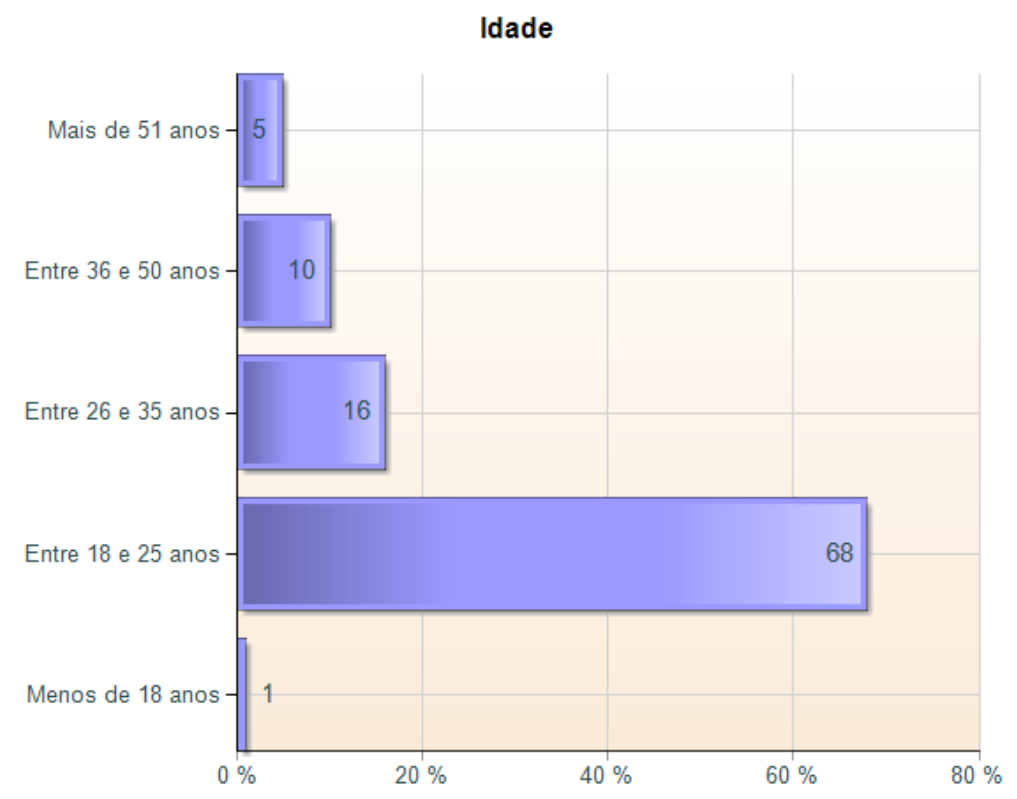

Figura 2 - Idade dos entrevistados.

Fonte: Pesquisa de campo, 2009. 


\subsection{Comportamento quanto ao uso do celular pelos entrevistados}

Outro objetivo da pesquisa é identificar a como os usuários brasileiros utilizam o celular e qual sua familiaridade com a tecnologia Bluetooth.

A pesquisa "2008 Latin America Mobile Attitude Usage Study", realizada em agosto de 2008, no México, Argentina e Brasil, os jovens são os usuários mais ativos do celular e utilizam os recursos disponíveis pelos aparelhos com maior intensidade.

Ainda segundo essa pesquisa, o número de aparelhos médio por família na América Latina é de 3,8 telefones, e dois a cada três pessoas são usuárias de telefone celular. Além disso, o celular é considerado um item de muita importância pelos seus usuários, sendo que $66 \%$ dos entrevistados classificaram os aparelhos como muito importantes.

A figura 4.2 mostra que $95 \%$ dos entrevistados são usuários de celular a mais de 3 anos, sendo que $46 \%$ deles utilizam o aparelho há mais de 8 anos. Dessa maneira, pode-se afirmar que a maioria dos respondentes são usuários experientes e com bastante familiaridade com esse tipo de tecnologia.

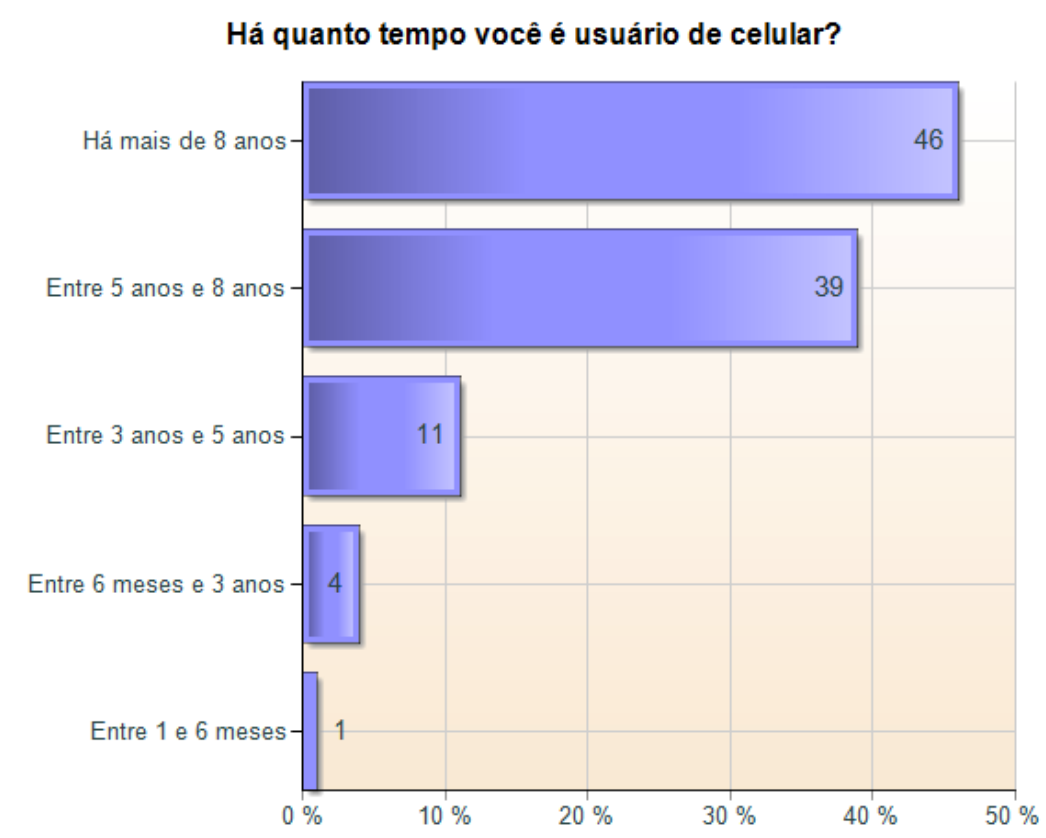

Figura 3 - Período de uso de celular pelos entrevistados.

Fonte: Pesquisa de campo, 2009. 
As principais marcas de celular utilizadas pelos entrevistados são Nokia, $41 \%$, e Motorola, 30\%. LG, Sony Ericsson e Samsung são responsáveis por 37\% e outras marcas como Apple, HTC e Blackberry respondem por $10 \%$ dos entrevistados. Deve-se considerar que os entrevistados podem possuir mais de um aparelho celular, sendo que dentre os entrevistados, $40 \%$ possuem mais de um aparelho celular, sendo que $33 \%$ do total possuem dois aparelhos. Vivo (30\%), Claro (26\%), Oi/BrT (26\%) e TIM (33\%) são as principais operadoras utilizadas.

Ainda na pesquisa pode-se observar que muitos usuários utilizam duas operadoras ou mais para aproveitar as vantagens e promoções que cada uma oferece e poderem economizar nas ligações e envio de SMS por exemplo.

Com relação aos recursos do celular e sua importância na hora da compra de um aparelho novo, na Tabela 4.1 pode-se observar as diferenças por grupo de idade em suas preferências. Os respondentes tiveram que classificar os recursos preferíveis dando uma nota de 1 a 10 , sendo que 1 representava a nota mais baixa e 10 a nota mais alta.

Importância dos recursos no momento da compra de um aparelho

$\begin{array}{lcllr}\text { \# Entre 18 e 25 anos } & \text { Nota } & \text { \# Entre } 36 \text { e } 50 \text { anos } & \text { Nota } \\ \mathbf{1} \text { Mensagem de texto (SMS) } & 9 & \mathbf{1} \text { Mensagem de texto (SMS) } & 8 \\ \mathbf{2} \text { MP3 Player } & 8 & \mathbf{2} \text { Câmera Fotográfica } & 7 \\ \mathbf{3} \text { Câmera Fotográfica } & 8 & \mathbf{3} \text { MP3 Player } & 6 \\ \mathbf{4} \text { Bluetooth } & 7 & \mathbf{4} \text { Bluetooth } & 6 \\ \mathbf{5} \text { Fone de Ouvido } & 6 & \mathbf{5} \text { Fone de Ouvido } & 6 \\ \mathbf{6} \text { Mensagem de foto/vídeo (MMS) } & 6 & \mathbf{6} \text { Mensagem de foto/vídeo (MMS) } & 6 \\ \mathbf{7} \text { Internet Móvel (WAP) } & 4 & \mathbf{7} \text { Internet Móvel (WAP) } & 5 \\ \text { \# Entre 26 e 35 anos } & \text { Nota } & \text { \# Mais de 51 anos } & \text { Nota } \\ \mathbf{1} \text { Mensagem de texto (SMS) } & 9 & \mathbf{1} \text { Câmera Fotográfica } & 7 \\ \mathbf{2} \text { Câmera Fotográfica } & 8 & \mathbf{2} \text { Mensagem de texto (SMS) } & 7 \\ \mathbf{3} \text { Bluetooth } & 7 & \mathbf{3} \text { Internet Móvel (WAP) } & 6 \\ \mathbf{4} \text { MP3 Player } & 7 & \mathbf{4} \text { Mensagem de foto/vídeo (MMS) } & 5 \\ \mathbf{5} \text { Fone de Ouvido } & 7 & \mathbf{5} \text { Fone de Ouvido } & 5 \\ \mathbf{6} \text { Mensagem de foto/vídeo (MMS) } & \mathbf{6} & \mathbf{6} \text { Bluetooth } & 5 \\ \mathbf{7} \text { Internet Móvel (WAP) } & 6 & \mathbf{7} \text { MP3 Player } & 4\end{array}$

Tabela 2- Importância dos recursos do celular no momento da compra de um aparelho novo e faixa etária.

Fonte: Pesquisa de campo, 2009. 
Enquanto o recurso Mensagem de Texto (SMS) é considerado o mais importante por todos os grupos de idade até os 50 anos, os usuários com 51 anos ou mais consideram a Câmera Fotográfica como mais importante. Os recursos Câmera Fotográfica, Mensagem de Texto (SMS), MP3 Player e Bluetooth são os quatro mais importantes entre os usuários de 18 a 50 anos, trocando de posição entre as faixas etárias, porém suas notas são sempre próximas e destoam dos dois demais recursos.

É interessante notar que a Internet Móvel (WAP), é o recurso menos valorizado entre os mais jovens, com notas bastante inferiores aos outros recursos, enquanto para os usuários com mais de 51 anos é o terceiro mais importante.

De maneira geral, os jovens entre 18 e 25 anos e adultos entre 26 e 35 anos atribuíram notas maiores a todos os recursos. $\mathrm{O}$ que pode significar uma importância maior dada pelos mais jovens aos novos recursos e suas aplicações.

As mulheres entrevistadas valorizam a Mensagem de Texto (SMS), a Mensagem de Foto/Vídeo e o Bluetooth cerca de um ponto na nota média a mais que os homens. Enquanto que os homens valorizam a Internet Móvel (WAP) cerca de um ponto na nota média a mais que as mulheres. Isso pode representar uma importância maior pelas mulheres quanto a celulares com mais recursos e tecnologias mais avançadas.

A freqüência de utilização dos recursos Mensagem de Texto (SMS), Internet Móvel (WAP) e Bluetooth também foi analisada. Por serem os três principais meios de publicidade do mobile marketing hoje, é fundamental saber como os usuários de celular utilizam essas ferramentas.

Segundo a pesquisa "2008 Latin America Mobile Attitude Usage Study", 65\% dos brasileiros utilizam o SMS, sendo que $31 \%$ utilizam diariamente e $21 \%$ semanalmente. Ainda segundo a pesquisa, a Internet Móvel é utilizada por $24 \%$ dos brasileiros, e $14 \%$ ao menos uma vez por semana.

Entre os entrevistados deste trabalho, de maneira geral, o recurso mais utilizado é a Mensagem de Texto (SMS), somente 3\% não utilizam o recurso. 49\% dos entrevistados utilizam o recurso diariamente e $27 \%$ utilizam entre 2 a 5 dias na semana. Além disso, os jovens e adultos entre os 18 e 35 anos utilizam o recurso de maneira mais freqüente, sendo que $54 \%$ deles enviam ou recebem mensagens SMS 
diariamente. Entre os jovens de 18 a 25 anos o uso é mais intenso ainda, $53 \%$ deles utilizam o recurso diariamente e $31 \%$ utilizam entre 2 a 5 dias na semana.

A Tabela 4.2 mostra os resultados obtidos por faixa etária e no total quanto a freqüência de utilização desses recursos. De maneira geral, os entrevistados com mais de 36 anos utilizam esses recurso com menos freqüência. Esse cenário, no entanto, é passível de mudança, uma vez que os jovens hoje não deixam de utilizar as ferramentas que o celular proporciona com o passar do tempo.

A maioria das pessoas possui Internet Móvel no celular, 94\% dos entrevistados, porém é utilizada por somente $25 \%$ dos respondentes ao menos uma vez por mês. Quanto ao Bluetooth, $88 \%$ das pessoas possuem o recurso no aparelho móvel, mas $26 \%$ não o utilizam, $36 \%$ utilizam menos de quatro vezes ao mês e $26 \%$ uma vez ou mais por semana.

Observa-se que o Bluetooth é uma maneira de comunicação entre celulares e outros aparelhos eletrônicos, melhor utilizado e mais conhecido que a Internet Móvel, sendo uma alternativa interessante ao mobile marketing.

\begin{tabular}{|c|c|c|c|c|c|}
\hline \multicolumn{6}{|c|}{ Frequencia de uso dos recursos para mobile marketing por faixa etária } \\
\hline Mensagem de Texto (SMS) & Entre 18 e 25 anos & Entre 26 e 35 anos & Entre 36 e 50 anos & Mais de 51 anos & TOTAL \\
\hline Todos os dias & $53 \%$ & $54 \%$ & $29 \%$ & $20 \%$ & $49 \%$ \\
\hline Entre 2 a 5 dias na semana & $31 \%$ & $19 \%$ & $16 \%$ & $20 \%$ & $27 \%$ \\
\hline Uma vez a cada semana & $11 \%$ & $17 \%$ & $10 \%$ & $7 \%$ & $12 \%$ \\
\hline Menos de quatro vezes ao mês & $4 \%$ & $8 \%$ & $35 \%$ & $27 \%$ & $9 \%$ \\
\hline Não utilizo este recurso & $0 \%$ & $2 \%$ & $10 \%$ & $27 \%$ & $3 \%$ \\
\hline Internet Móvel (WAP) & Entre 18 e 25 anos & Entre 26 e 35 anos & Entre 36 e 50 anos & Mais de 51 anos & TOTAL \\
\hline Todos os dias & $6 \%$ & $6 \%$ & $6 \%$ & $0 \%$ & $6 \%$ \\
\hline Entre 2 a 5 dias na semana & $1 \%$ & $10 \%$ & $3 \%$ & $0 \%$ & $3 \%$ \\
\hline Uma vez a cada semana & $1 \%$ & $4 \%$ & $3 \%$ & $0 \%$ & $2 \%$ \\
\hline Menos de quatro vezes ao mês & $14 \%$ & $17 \%$ & $16 \%$ & $13 \%$ & $14 \%$ \\
\hline Não utilizo este recurso & $73 \%$ & $56 \%$ & $65 \%$ & $60 \%$ & $69 \%$ \\
\hline Não tenho este recurso no meu celular & $4 \%$ & $6 \%$ & $6 \%$ & $27 \%$ & $6 \%$ \\
\hline Bluetooth & Entre 18 e 25 anos & Entre 26 e 35 anos & Entre 36 e 50 anos & Mais de 51 anos & TOTAL \\
\hline Todos os dias & $1 \%$ & $8 \%$ & $6 \%$ & $0 \%$ & $3 \%$ \\
\hline Entre 2 a 5 dias na semana & $8 \%$ & $13 \%$ & $6 \%$ & $0 \%$ & $8 \%$ \\
\hline Uma vez a cada semana & $16 \%$ & $17 \%$ & $13 \%$ & $0 \%$ & $15 \%$ \\
\hline Menos de quatro vezes ao mês & $42 \%$ & $27 \%$ & $16 \%$ & $20 \%$ & $36 \%$ \\
\hline Não utilizo este recurso & $20 \%$ & $25 \%$ & $55 \%$ & $60 \%$ & $26 \%$ \\
\hline Não tenho este recurso no meu celular & $13 \%$ & $10 \%$ & $3 \%$ & $20 \%$ & $12 \%$ \\
\hline
\end{tabular}

Tabela 3 - Freqüência de uso dos recursos SMS, WAP e Bluetooth e faixa etária.

Fonte: Pesquisa de campo, 2009. 
As mulheres entrevistadas utilizam o SMS de maneira mais freqüente que os homens, $56 \%$ contra $42 \%$ diariamente. Eles, no entanto, utilizam a Internet Móvel e o Bluetooth com maior freqüência. Ainda que de maneira menos freqüente as mulheres utilizam o Bluetooth mais que os homens, uma vez que $30 \%$ deles não utilizam o recurso, contra $23 \%$ do público feminino.

Frequencia de uso dos recursos para mobile marketing por sexo

\begin{tabular}{|c|c|c|c|c|c|c|}
\hline \multirow{2}{*}{ Frequencia de utilização dos recursos do celular } & \multicolumn{2}{|c|}{ Mensagem de Texto (SMS) } & \multicolumn{2}{|c|}{ Internet Móvel (WAP) } & \multicolumn{2}{|c|}{ Bluetooth } \\
\hline & Mulheres & Homens & Mulheres & Homens & Mulheres & Homens \\
\hline Todos os dias & $56 \%$ & $42 \%$ & $4 \%$ & $8 \%$ & $1 \%$ & $5 \%$ \\
\hline Entre 2 a 5 dias na semana & $23 \%$ & $32 \%$ & $1 \%$ & $6 \%$ & $8 \%$ & $8 \%$ \\
\hline Uma vez a cada semana & $12 \%$ & $11 \%$ & $2 \%$ & $2 \%$ & $17 \%$ & $12 \%$ \\
\hline Menos de quatro vezes ao mês & $8 \%$ & $10 \%$ & $9 \%$ & $20 \%$ & $40 \%$ & $33 \%$ \\
\hline Não utilizo este recurso & $1 \%$ & $5 \%$ & $78 \%$ & $58 \%$ & $23 \%$ & $30 \%$ \\
\hline Não tenho este recurso no meu celular & $0 \%$ & $0 \%$ & $6 \%$ & $6 \%$ & $12 \%$ & $12 \%$ \\
\hline
\end{tabular}

Tabela 4 - Freqüência de uso dos recursos SMS, WAP e Bluetooth e sexo.

Fonte: Pesquisa de campo, 2009.

Quanto ao conhecimento sobre a tecnologia Bluetooth, somente $10 \%$ dos entrevistados disse não conhecer a ferramenta. $25 \%$ sabe realizar qualquer operação que o Bluetooth oferece, $50 \%$ sabe utilizar alguns recursos da ferramenta e $15 \%$ sabe ativar o recurso.

Os entrevistados com mais de 36 anos são quem tem menos familiaridade com o recurso. Somente $2 \%$ dos entrevistados entre 26 e 35 anos, e $7 \%$ entre 18 e 25 anos não conhece a ferramenta, contra $26 \%$ entre 36 e 50 anos e $40 \%$ com mais de 51 anos. 


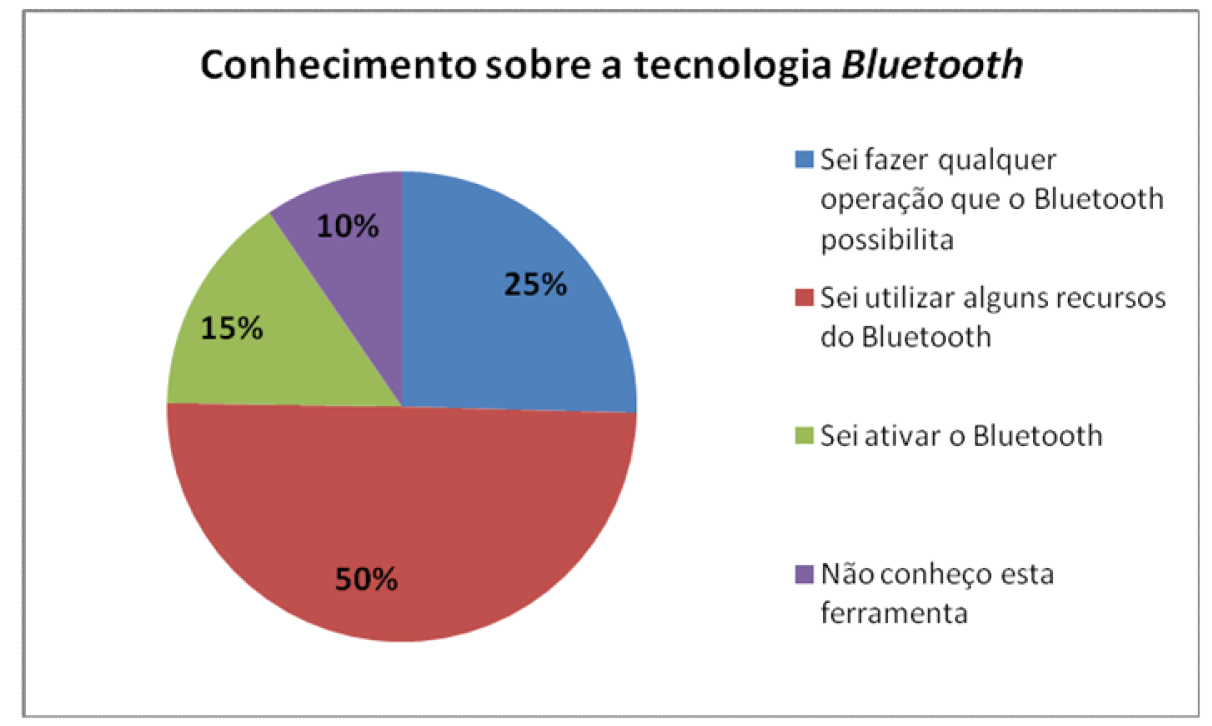

Figura 4 - Conhecimento sobre a tecnologia Bluetooth.

Fonte: Pesquisa de campo, 2009

\begin{tabular}{|c|c|c|c|c|c|}
\hline & Entre 18 e 25 anos & Entre 26 e 35 anos & Entre 36 e 50 anos & Mais de 51 anos & Total \\
\hline $\begin{array}{l}\text { Sei fazer qualquer operação que o } \\
\text { Bluetooth possibilita }\end{array}$ & $25 \%$ & $35 \%$ & $19 \%$ & $7 \%$ & $25 \%$ \\
\hline $\begin{array}{l}\text { Sei utilizar alguns recursos do } \\
\text { Bluetooth }\end{array}$ & $55 \%$ & $48 \%$ & $35 \%$ & $20 \%$ & $50 \%$ \\
\hline Sei ativar o Bluetooth & $13 \%$ & $15 \%$ & $19 \%$ & $33 \%$ & $15 \%$ \\
\hline Não conheço esta ferramenta & $7 \%$ & $2 \%$ & $26 \%$ & $40 \%$ & $10 \%$ \\
\hline
\end{tabular}

Tabela 5 - Conhecimento sobre a tecnologia Bluetooth e faixa etária.

Fonte: Pesquisa de campo, 2009

De maneira geral os entrevistados dão maior importância aos recursos Mensagem de Texto (SMS), Câmera Fotográfica, MP3 Player e Bluetooth. Sendo que a Mensagem de Texto é o recurso mais utilizado entre as ferramentas de mobile marketing, e o Bluetooth tem grande aceitação entre os entrevistados de 18 e 35 anos.

\subsection{A aceitabilidade dos entrevistados ao marketing via Bluetooth}

O objetivo principal do trabalho foi identificar a aceitabilidade dos usuários brasileiros de celular ao marketing via Bluetooth. A pesquisa "2008 Latin America Mobile 
Attitude Usage Study", indicou que a tecnologia Bluetooth é considerada de alta importância pelos brasileiros quanto à escolha de seus telefones móveis.

Quando questionados se gostariam de receber propagandas pelo celular, somente $3 \%$ dos entrevistados disse que sim e $47 \%$ respondeu que não gostaria. No entanto, $28 \%$ respondeu que talvez, caso pudesse escolher a quantidade de mensagens e assuntos do seu interesse, e $22 \%$ respondeu que talvez aceitassem, se tivessem benefícios como descontos e prêmios. Assim, 53\% dos entrevistados estariam dispostos de alguma maneira a receber propagandas pelo telefone móvel (Figura 4.4).

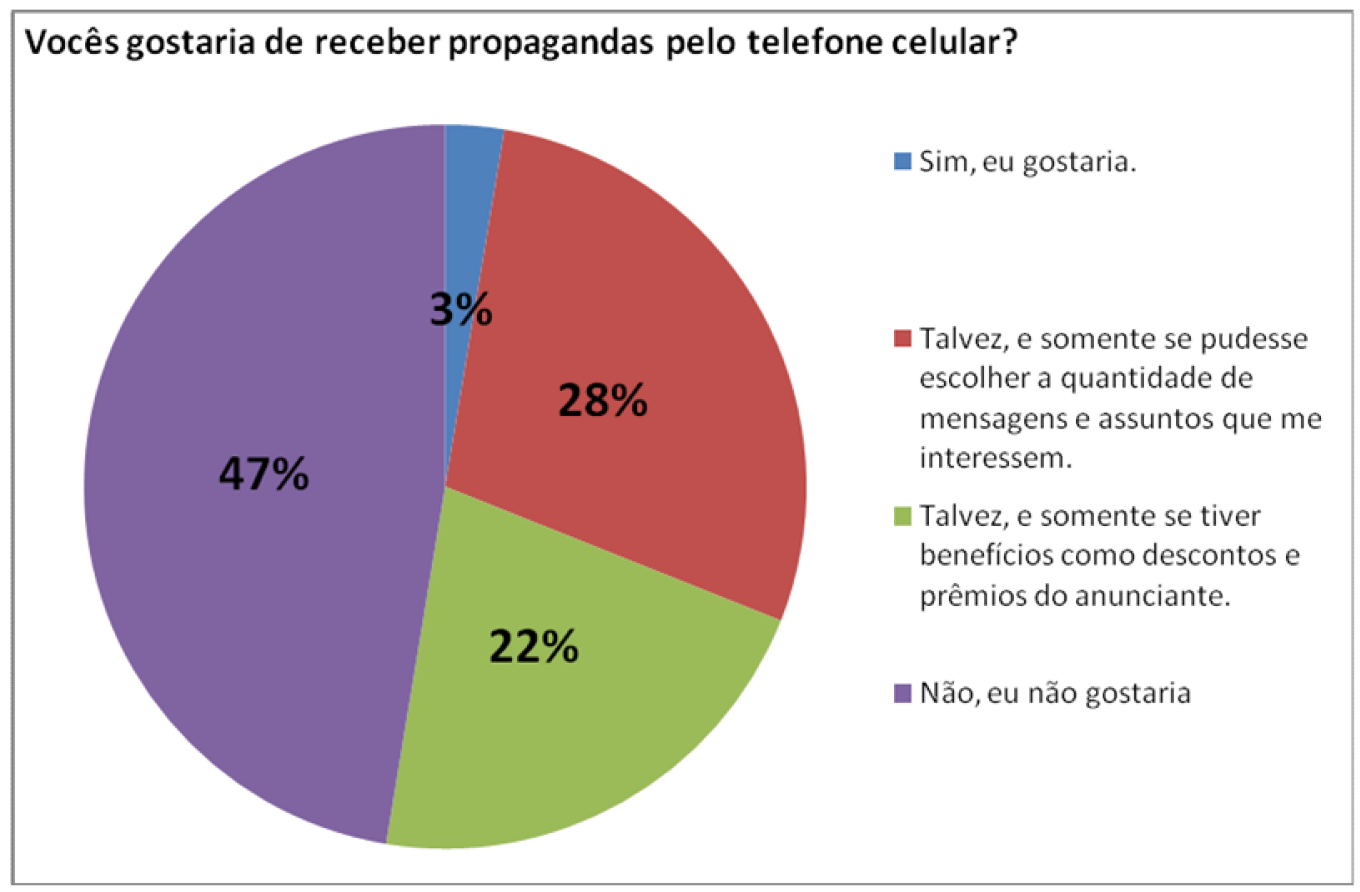

Figura 5 - Desejo de receber propagandas pelo celular.

Fonte: Pesquisa de campo, 2009

A menor rejeição as propagandas pelo celular foi dos entrevistados com mais de 51 anos, $40 \%$ disseram que não gostariam de receber publicidade no telefone, contra $65 \%$ dos entrevistados entre 36 e 50 anos, $48 \%$ entre 26 e 35 anos e $45 \%$ entre 18 e 25 anos. Ainda que com maior rejeição, os entrevistados entre 36 e 50 anos também apresentaram maior aceitação incondicional a publicidade, $6 \%$ deles 
responderam que sim, gostariam de receber propaganda pelo celular. Enquanto que aqueles com mais de 51 anos, nenhum respondeu que sim incondicionalmente.

Aceitabilidade as propagandas pelo telefone celular por faixa etária

\begin{tabular}{|c|c|c|c|c|}
\hline $\begin{array}{l}\text { Você gostaria de receber propagandas pelo } \\
\text { telefone celular? }\end{array}$ & $\begin{array}{l}\text { Entre } 18 \text { e } 25 \\
\quad \text { anos }\end{array}$ & $\begin{array}{l}\text { Entre } 26 \text { e } 35 \\
\quad \text { anos }\end{array}$ & $\begin{array}{l}\text { Entre } 36 \text { e } 50 \\
\quad \text { anos }\end{array}$ & $\begin{array}{l}\text { Mais de } 51 \\
\quad \text { anos }\end{array}$ \\
\hline Sim, eu gostaria. & $2 \%$ & $4 \%$ & $6 \%$ & $0 \%$ \\
\hline $\begin{array}{l}\text { Talvez, e somente se pudesse escolher a } \\
\text { quantidade de mensagens e assuntos que me } \\
\text { interessem. }\end{array}$ & $30 \%$ & $23 \%$ & $19 \%$ & $33 \%$ \\
\hline $\begin{array}{l}\text { Talvez, e somente se tiver benefícios como } \\
\text { descontos e prêmios do anunciante. }\end{array}$ & $22 \%$ & $25 \%$ & $10 \%$ & $27 \%$ \\
\hline Não, eu não gostaria & $45 \%$ & $48 \%$ & $65 \%$ & $40 \%$ \\
\hline
\end{tabular}

Tabela 6 - Aceitabilidade as propagandas pelo telefone por faixa etária.

Fonte: Pesquisa de campo, 2009

Os homens tiveram maior rejeição quanto a receber publicidade no celular. $50 \%$ dos homens entrevistados disseram que não gostariam de receber propaganda no telefone, enquanto $45 \%$ das mulheres entrevistadas responderam que não também.

Aceitabilidade as propagandas pelo telefone celular por formação

\begin{tabular}{l|c|c|c|c}
$\begin{array}{l}\text { Você gostaria de receber propagandas pelo } \\
\text { telefone celular? }\end{array}$ & $\begin{array}{c}\text { Fundamental } \\
\text { completo }\end{array}$ & $\begin{array}{c}\text { Superior } \\
\text { incompleto }\end{array}$ & $\begin{array}{c}\text { Superior } \\
\text { completo }\end{array}$ & Pós-Graduação \\
$\begin{array}{l}\text { Sim, eu gostaria. } \\
\begin{array}{l}\text { Talvez, e somente se pudesse escolher a } \\
\text { quantidade de mensagens e assuntos que me } \\
\text { interessem. }\end{array}\end{array} \quad 22 \%$ & $30 \%$ & $28 \%$ & $26 \%$ \\
$\begin{array}{l}\text { Talvez, e somente se tiver benefícios como } \\
\text { descontos e prêmios do anunciante. }\end{array}$ & $11 \%$ & $21 \%$ & $28 \%$ & $17 \%$ \\
Não, eu não gostaria & $67 \%$ & $49 \%$ & $41 \%$ & $50 \%$
\end{tabular}

Tabela 7 - Aceitabilidade as propagandas pelo telefone por formação.

Fonte: Pesquisa de campo, 2009

Os entrevistados foram questionados a respeito dos meios preferidos para receber publicidade pelo celular. As opções eram Mensagem de Texto (SMS), Mensagem de Foto/Vídeo (MMS), Bluetooth, Internet Móvel e caso não tivessem interesse em receber publicidade pelo celular poderiam indicar isso também. Os respondentes poderiam também indicar mais de uma alternativa. 
O meio preferido para receber publicidade pelo celular foi o SMS com $45 \%$ das escolhas, o MMS ficou em segundo com $17 \%$ das indicações, seguido por Bluetooth com $11 \%$ e Internet Móvel com 2\%.

Ainda que quando perguntados se desejariam receber mensagens publicitárias pelo celular $47 \%$ dos entrevistados responderam que não, quando foram colocadas opções de meios para receber propaganda no telefone móvel, 44\% responderam que não teria interesse. Isso demonstra que ao saber das possibilidades para o recebimento de publicidade no celular, a rejeição é menor entre os entrevistados. $12 \%$ dos entrevistados que disseram não desejar receber propagandas pelo celular na questão anterior, indicaram meios para preferidos para a publicidade ao invés de indicar que não tinham interesse em receber informações pelo celular.

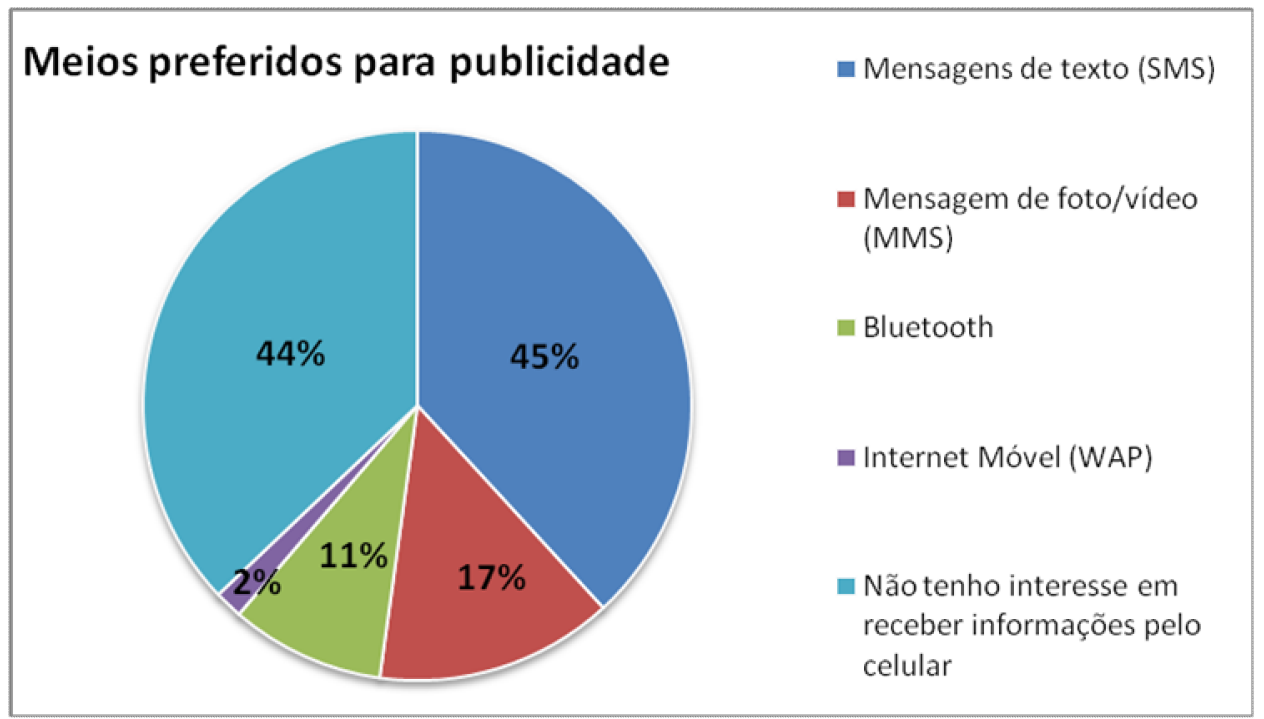

Figura 6 - Meios preferidos para publicidade no celular.

Fonte: Pesquisa de campo, 2009

Entre os jovens e adultos com idade de 18 a 35 anos, a rejeição é menor ainda, com $37 \%$ dos entrevistados respondendo que não tem interesse em receber informações pelo celular. O meio preferido por todas as faixas etárias é também a Mensagem de Texto. O Bluetooth, porém ganha destaque entre os entrevistados de 18 a 25 anos, com $11 \%$ das indicações de preferência. 
Meios preferidos para publicidade por faixa etária

\begin{tabular}{|c|c|c|c|c|}
\hline Meios preferidos para publicidade & $\begin{array}{l}\text { Entre } 18 \text { e } 25 \\
\quad \text { anos }\end{array}$ & $\begin{array}{l}\text { Entre } 26 \text { e } 35 \\
\quad \text { anos }\end{array}$ & $\begin{array}{l}\text { Entre } 36 \text { e } 50 \\
\text { anos }\end{array}$ & Mais de 51 anos \\
\hline Mensagens de texto (SMS) & $39 \%$ & $35 \%$ & $32 \%$ & $50 \%$ \\
\hline Mensagem de foto/vídeo (MMS) & $14 \%$ & $23 \%$ & $3 \%$ & $13 \%$ \\
\hline Bluetooth & $11 \%$ & $4 \%$ & $3 \%$ & $6 \%$ \\
\hline Internet Móvel (WAP) & $2 \%$ & $0 \%$ & $6 \%$ & $0 \%$ \\
\hline $\begin{array}{l}\text { Não tenho interesse em receber } \\
\text { informações pelo celular }\end{array}$ & $35 \%$ & $39 \%$ & $56 \%$ & $31 \%$ \\
\hline
\end{tabular}

Tabela 8 - Meios preferidos para publicidade por faixa etária.

Fonte: Pesquisa de campo, 2009.

As mulheres entrevistadas têm maior preferência em receber publicidade via SMS do que os homens. $42 \%$ delas indicaram esse meio como preferido enquanto $34 \%$ dos homens fizeram essa escolha. Já o Bluetooth tem maior preferência entre os homens, $11 \%$ deles escolheram a tecnologia como preferencial, contra $8 \%$ das mulheres.

A menor rejeição a publicidade pelo celular está entre aqueles que escolheram o Bluetooth como meio preferido para receber propaganda. Somente 3\% dos entrevistados que indicaram essa tecnologia como preferência disseram não desejar receber propaganda pelo celular.

\begin{tabular}{|c|c|c|c|c|}
\hline \multirow[b]{2}{*}{$\begin{array}{l}\text { Você gostaria de receber propagandas pelo } \\
\text { telefone celular? }\end{array}$} & \multicolumn{4}{|c|}{ Meios preferidos para receber publicidade no celular. } \\
\hline & $\begin{array}{c}\text { Mensagem de Texto } \\
\text { (SMS) }\end{array}$ & $\begin{array}{l}\text { Mensagem de } \\
\text { Foto/Video }\end{array}$ & Bluetooth & $\begin{array}{l}\text { Internet Móvel } \\
\text { (WAP) }\end{array}$ \\
\hline Sim, eu gostaria. & $3 \%$ & $8 \%$ & $3 \%$ & $33 \%$ \\
\hline $\begin{array}{l}\text { Talvez, e somente se pudesse escolher a } \\
\text { quantidade de mensagens e assuntos que me } \\
\text { interessem. }\end{array}$ & $51 \%$ & $49 \%$ & $70 \%$ & $50 \%$ \\
\hline $\begin{array}{l}\text { Talvez, e somente se tiver benefícios como } \\
\text { descontos e prêmios do anunciante. }\end{array}$ & $35 \%$ & $39 \%$ & $24 \%$ & $0 \%$ \\
\hline Não, eu não gostaria & $11 \%$ & $4 \%$ & $3 \%$ & $17 \%$ \\
\hline
\end{tabular}

Tabela 9 - Aceitabilidade as propagandas pelo telefone celular e os meios preferido para receber publicidade no celular.

Fonte: Pesquisa de campo, 2009.

Quando questionados sobre quais conteúdos publicitários os entrevistados desejariam receber via Bluetooth, informações sobre eventos e notícias além de 
músicas foram os preferidos, com $18 \%$ das indicações cada. Nessa questão, os respondentes poderiam indicar uma ou mais opções.

$18 \%$ dos entrevistados disseram não pretender receber mensagens publicitárias via Bluetooth, o que demonstra pouca rejeição a esse tipo de tecnologia, principalmente quando se compara aos $47 \%$ de rejeição quando a pergunta dizia simplesmente sobre receber publicidade pelo celular. Descontos e ofertas especiais, com $15 \%$ das indicações e promoções de produtos e serviços, com 13\%, também foram preferidos.

Entre os jovens de 18 a 25 anos, o tipo de conteúdo preferido foi música, com 19\% das indicações, o índice de rejeição - aqueles que não pretendem receber publicidade pelo Bluetooth - foi o menor, $15 \%$, sendo esse público o mais aberto a esse tipo de propaganda. Para as demais faixas etárias informações sobre eventos e notícias foi o tipo de mensagem preferida, com $21 \%$, Seguida por descontos e ofertas especiais, $15 \%$.

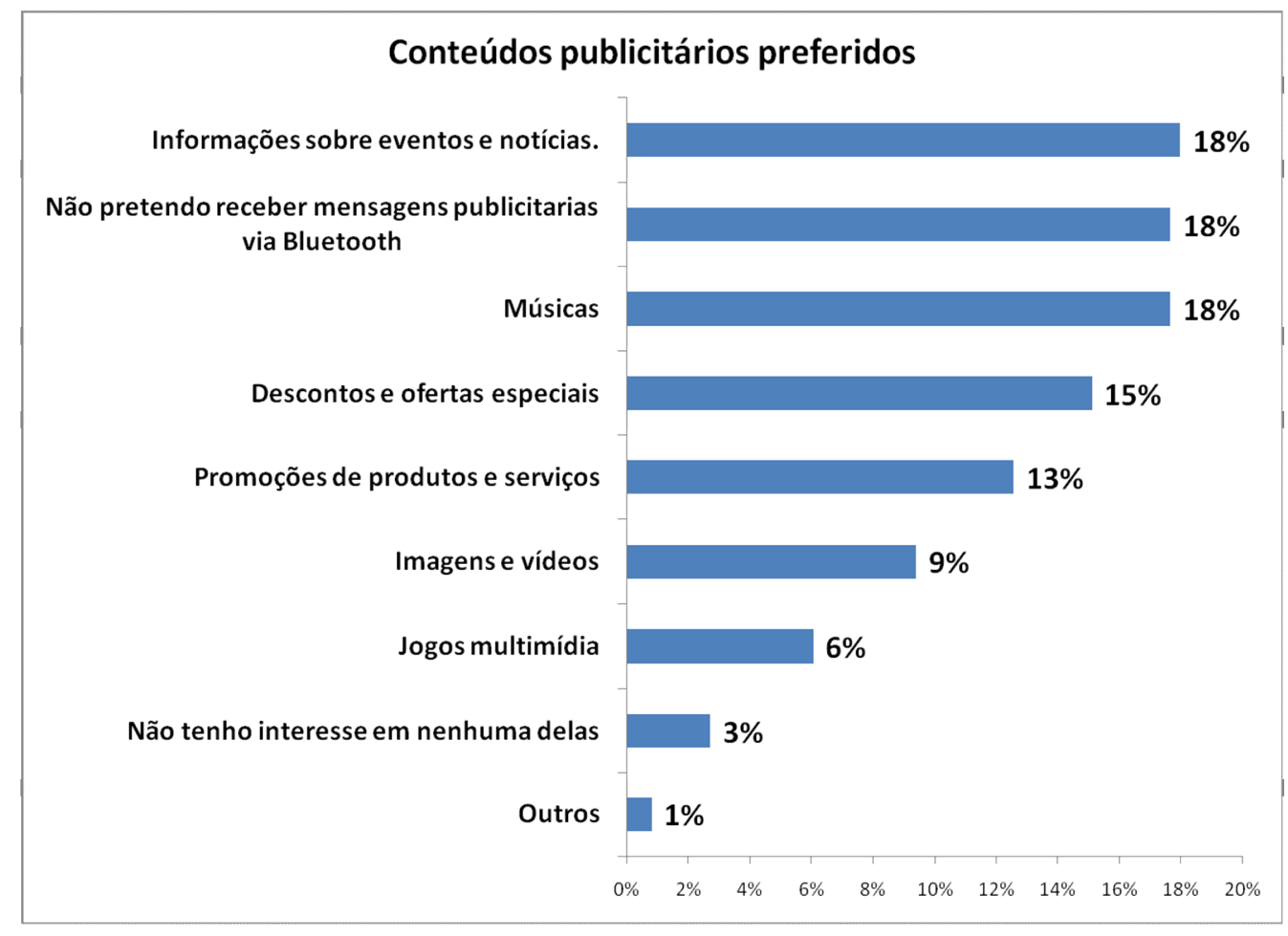

Figura 7 - Conteúdos publicitários preferidos.

Fonte: Pesquisa de campo, 2009. 
Os entrevistados também foram colocados em uma situação específica: qual atitude tomariam se estivessem em um centro comercial, e fosse solicitado que ativassem o Bluetooth do celular para receber ofertas e serviços das lojas. $20 \%$ dos entrevistados disseram que ativaria o recurso no celular, $48 \%$ ativaria, desde que pudesse escolher quais tipos de informações e de quais anunciantes receberia as mensagens e $32 \%$ não ativaria o Bluetooth.

Isso demonstra uma aceitação muito boa ao marketing via Bluetooth. $68 \%$ dos entrevistados concordariam em ativar o Bluetooth para receber publicidade dos comerciantes locais. No entanto, deve-se observar a necessidade de customização das mensagens, pois $70 \%$ daqueles que ativariam o recurso, só o fariam caso pudessem escolher as mensagens que iram receber.

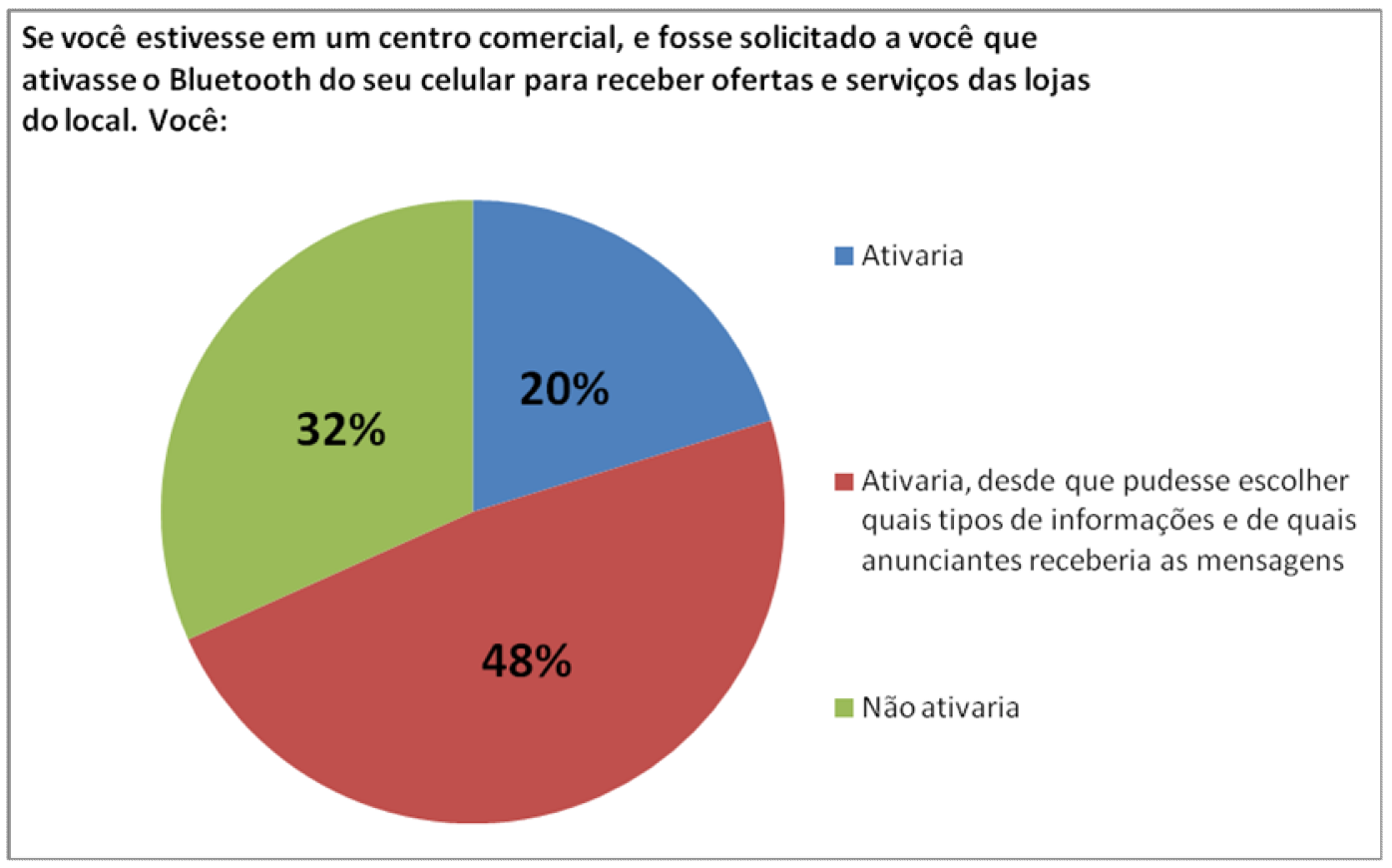

Figura 8 - Solicitação para ativar o Bluetooth em um centro comercial.

Fonte: Pesquisa de campo, 2009.

Entre homens e mulheres, a rejeição foi igual: $32 \%$ dos homens e mulheres entrevistados não ativariam o Bluetooth. Os homens, porém foram mais receptivos, 
sendo que $22 \%$ deles ativariam o recurso de maneira incondicional, contra $19 \%$ das mulheres.

A Tabela 4.9 mostra que a faixa etária com maior aceitação a ativar o Bluetooth em um centro comercial é de 26 a 35 anos, com 25\% dos entrevistados afirmando que ativariam o Bluetooth, e $46 \%$ dizendo que ativariam caso pudessem escolher os conteúdos que iriam receber. De maneira geral os jovens se mostram mais receptivos a esse tipo de publicidade, entre 19 e 35 anos $70 \%$ dos entrevistados ativariam o Bluetooth caso fossem solicitados a fazer em um centro comercial. Já entre os entrevistados acima de 36 anos $57 \%$ não ativariam o recurso.

Se você estivesse em um centro comercial, e fosse solicitado a você que ativasse o Bluetooth do seu celular para receber ofertas e serviços das lojas do local. Você:

\begin{tabular}{|c|c|c|c|c|}
\hline & $\begin{array}{c}\text { Entre } 18 \text { e } 25 \\
\text { anos }\end{array}$ & $\begin{array}{c}\text { Entre } 26 \text { e } 35 \\
\text { anos }\end{array}$ & $\begin{array}{c}\text { Entre } 36 \text { e } 50 \\
\text { anos }\end{array}$ & $\begin{array}{c}\text { Mais de } 51 \\
\text { anos }\end{array}$ \\
\hline Ativaria & $19 \%$ & $25 \%$ & $23 \%$ & $20 \%$ \\
\hline $\begin{array}{l}\text { Ativaria, desde que pudesse escolher } \\
\text { quais tipos de informações e de quais } \\
\text { anunciantes receberia as mensagens }\end{array}$ & $50 \%$ & $46 \%$ & $39 \%$ & $33 \%$ \\
\hline Não ativaria & $31 \%$ & $29 \%$ & $39 \%$ & $47 \%$ \\
\hline
\end{tabular}

Tabela 10 - Solicitação para ativar o Bluetooth em um centro comercial.

Fonte: Pesquisa de campo, 2009.

Entre os entrevistados que responderam não desejar receber propagandas pelo celular quando questionados somente a respeito disso, $49 \%$ disseram que ativariam o Bluetooth caso fosse solicitado para receber informações publicitárias, sendo que 24\% dos entrevistados manteve a mesma opinião, ou seja, não deseja receber publicidade no celular e não ativaria o Bluetooth para esse fim caso fosse solicitado.

O Bluetooth é então melhor aceito quando colocado em uma situação que o usuário pode ou não aceitar receber mensagens, o que demonstra a necessidade de aprovação do consumidor para o envio de mensagens. 


\section{CONSIDERAÇÕES FINAIS}

O presente estudo trouxe uma discussão importante para o marketing em um cenário de novas tecnologias de comunicação e como essas mudanças influenciam no comportamento do consumidor. Como o mobile marketing é um assunto que tem despertado grande interesse recentemente, ainda carece de pesquisas e estudos para melhor compreensão de suas vantagens, possibilidades e usos.

Esse trabalho procurou entender a aceitabilidade dos usuários brasileiros de celular ao mobile marketing através da tecnologia Bluetooth. A pesquisa "2008 Latin America Mobile Attitude Usage Study", apontou essa tecnologia como bastante importante aos usuários brasileiros. Assim, buscou-se identificar como os usuários brasileiros utilizam seu aparelho celular, como se sentem ao receber mensagens publicitárias através do aparelho, em especial através da tecnologia Bluetooth.

Com base no objetivo geral da pesquisa, verificou-se que os brasileiros usuários de telefone celular estão bastante receptivos ao marketing através do Bluetooth. Inclusive a tecnologia mostrou maior aceitabilidade do que a idéia genérica de receber propaganda pelo celular, ou seja, quando questionados se gostariam de receber mensagens publicitárias pelo celular através do Bluetooth, os entrevistados mostraram maior aceitação do que quanto a pergunta referia-se simplesmente a propagandas pelo celular, seja qual for o meio ou tecnologia empregada.

Ainda que com maior aceitabilidade, os usuários colocaram como condição para receber publicidade pelo Bluetooth, a possibilidade de escolher quais os anunciantes, tipos e quantidade de mensagens enviadas. Dessa maneira, fica evidente a necessidade de permissão dos usuários para o envio de mensagens. Ainda quanto ao mobile marketing de maneira geral, foi identificado também a possibilidade de oferecer prêmios e descontos aos usuários que dessa maneira aceitariam receber propagandas nos seus telefones.

Os entrevistados de maneira geral mostram-se familiarizados com a tecnologia Bluetooth, ainda que os jovens mostraram-se maior facilidade no seu uso. Os jovens e adultos entre 18 e 36 anos foram os que se mostraram mais receptivos ao mobile marketing e também com maior familiaridade com o uso do celular e suas funcionalidades. Essa facilidade no uso do aparelho móvel é essencial para sucesso 
nas campanhas de mobile marketing e possibilita uma receptividade maior as possibilidades de envio de conteúdo móvel.

Quando colocados em uma situação possível de campanha de mobile marketing através do Bluetooth - a possibilidade de receber mensagens publicitárias em um centro comercial através da ativação da tecnologia no celular - a aceitação foi grande e se mostrou muito superior a aceitabilidade do mobile marketing de maneira geral. Demonstrando que o Bluetooth oferece uma barreira menor para atingir o consumidor através desse novo tipo de marketing.

Em resumo o Bluetooth apresentou-se como uma alternativa viável e interessante ao mobile marketing, uma vez que diante do levantamento bibliográfico realizado, ficou evidente que o Bluetooth é uma tecnologia de baixo custo em relação a outras formas de marketing no celular, como o SMS, por exemplo, e permite possibilidade de ofertar conteúdos em diversos meios como vídeos, fotos e textos. Além disso, permite a criação de campanhas inovadoras e inteligentes que utilizam a interação entre o celular e seu usuário de forma criativa.

A pesquisa de campo concluiu que o brasileiro, além de possuir o recurso Bluetooth na maioria dos celulares, apresenta boa familiaridade com essa tecnologia. Além disso, os entrevistados demonstraram boa aceitabilidade ao uso do Bluetooth no celular para envio de publicidade, devendo ser observado no entanto a necessidade de permissão do consumidor para o envio de mensagens.

Esse estudo então permite uma visão inicial de um processo maior e mais complexo, que demanda novos estudos e quanto a um campo de interação de tecnologia e gestão em expansão rápida e crescente. Existe a possibilidade de trabalhos que procurem: desenvolver mecanismos de avaliação e mensuração, junto a modelos e métodos já existentes para identificar a efetividade de campanhas publicitárias dessa natureza; entender as possibilidades de uso da tecnologia de mobile marketing como diferencial competitivo; analisar aspectos de uma maior interação e articulção de mídia; personalizar e incrementar de maneira efetiva o dialogo e comunicação com o cliente.

Devido a escassez de estudos científicos no campo do mobile marketing no Brasil, além do seu caráter inovador, faz-se necessário algumas considerações para efeito de novos estudos. Observa-se que as aplicações do mobile marketing são bastante 
limitadas e no Brasil basicamente se resumem ao envio de mensagens de texto (SMS). As tecnologias utilizadas e as possibilidades oferecidas pelo mobile marketing são ainda desconhecidas. Para os consumidores usuários dessa mídia, a publicidade pelo celular trata-se apenas de promoções e ofertas especiais. Os benefícios reais e possibilidades que o mobile marketing pode trazer ainda são pouco entendidos tanto pelos consumidores como pelas empresas.

É preciso que novos estudos abordem mais diferentes possibilidades de campanhas utilizando o mobile marketing e procurem entender a percepção tanto dos consumidores finais como das agências de publicidade e empresas anunciantes, para que se tenham insumos sobre a aceitação desta nova ferramenta de relacionamento. Além disso, é necessário observar se os consumidores vislumbram uma oportunidade não só de receber ofertas e publicidade, mas sim uma chance de relacionar-se com as organizações que são clientes. É interessante também que outros estudos relacionem de forma profunda o mobile marketing com outras mídias e tecnologias, para entender até que ponto essa nova ferramenta de marketing é sustentável para a atração, fidelização e retenção de clientes. 


\section{REFERÊNCIAS}

ACEVEDO, C. R.; NOHARA, J J. Monografia no curso de administração: guia completo de conteúdo e forma: inclui normas atualizadas da ABNT, TCC, TGI, trabalhos de estágio, MBA, dissertações, teses. São Paulo: Atlas, 2007.

ALBRECHT, K. Revolução nos serviços: como as empresas podem revolucionar a maneira de tratar seus clientes. São Paulo: Pioneira, 2002.

AMMB - Associação de Marketing Móvel do Brasil. Disponível em <http://www.ammb.com.br/ammb.asp>. Acesso em 19 de abril de 2009.

ANATEL - Agencia Nacional de Telecomunicações. Disponível em <www.anatel.gov.br>. Acesso em 20 de Abril de 2009.

BARBETTA, P. A.. Estatística aplicada às Ciências Sociais. $5^{\text {a }}$ ed. Florianópolis: Ed. da UFSC, 2002.

BARDIN, L. Análise de conteúdo. Lisboa: Edições 70, 1977.

FACCHETTI, A. Mobile marketing: an analysis of key success factors and the European value chain. Int. J. Management and Decision Making. v. 6, n. 1, 2005.

GARCIA, M. T.; BARBOZA, V. A. Marketing de permissão. In: LAS CASAS, A. L. (Org.). Marketing móvel: tendências e oportunidades no marketing eletrônico. São Paulo: Saint Paul Editora, 2009. P. 115-134

GODIN, S. Marketing de permissão: transformando desconhecidos em amigos e amigos em clientes. Tradução de Flávia Rössler. Rio de Janeiro: Campus, 2000.

HAIG, M. Mobile marketing: The message Revolution. London: Kogan Page, 2002.

HANDS MOBILE. Disponível em< http://www.hands.com.br/site/portaldownloadhands.shtml >. Acesso em 15 de abril de 2009.

HUELSEN, P. O celular como ferramenta de comunicação. In: LAS CASAS, A. L. (Org.). Marketing móvel: tendências e oportunidades no marketing eletrônico. São Paulo: Saint Paul Editora, 2009. P. 175-190

KAVASSALIS, P. Mobile permission marketing - Framing the marketing Inquiry. Disponível em: <www.eltrun.aueb.gr/wrc/papers/kavassaliset\%al_itsmadrid.pdf>.

KOTLER, P.; ARMSTRONG, G. Princípios de marketing. Tradução Vera Whately. 7. ed - Rio de Janeiro: LTC, 2005.

KOTLER, P. Marketing para o século XXI: Como criar, conquistar e dominar mercados. Tradução Carlos Szlak.São Paulo: Ediouro, 2009.

KOTLER, P.; KELLER K. Administração de Marketing. 12a ed. São Paulo: Pearson Prentice Hall, 2006.

LÁRIOS, A. Estudo e Construção de Cenários para Telefonia Móvel Celular no Contexto Brasileiro. Porto Alegre, 2003. Dissertação (Mestrado). UFGRS.

LAS CASAS, A. L. Marketing de Serviços. $4^{\text {a }}$ ed. São Paulo: Atlas, 2006.

LAS CASAS, A. L. (Org.). Marketing móvel: tendências e oportunidades no marketing eletrônico. São Paulo: Saint Paul Editora, 2009. 
LAS CASAS, Alexandre Luzzi. Marketing: conceitos, exercícios e casos. 7. ed. São Paulo: Atlas, 2005.

LUCENA, L. O que é marketing móvel? In: LAS CASAS, A. L. (Org.). Marketing móvel: tendências e oportunidades no marketing eletrônico. São Paulo: Saint Paul Editora, 2009. P. 37-50

LUCENA, L. Tecnologias móveis disponíveis. In: LAS CASAS, A. L. (Org.). Marketing móvel: tendências e oportunidades no marketing eletrônico. São Paulo: Saint Paul Editora, 2009. P. 51-64

MALHOTRA, N. Pesquisa de marketing: uma orientação aplicada. $3^{a}$ ed. Porto Alegre: Bookman, 2001.

MATTAR, F. N. Pesquisa de marketing: metodologia, planejamento. $5^{\mathrm{a}}$ ed. São Paulo: Altas, 1999.

MARCONI, M. de A.; LAKATOS, E.M. Técnicas de pesquisa: planejamento e execução de pesquisas, amostras e técnicas de pesquisa, elaboração, análise e interpretação de dados. Atlas: São Paulo, 2002.

MCKENNA, R.. As cinco regras do novo marketing. In: Hsm Management. São Paulo. Ano 4, n.22, pp. 14 e 15, 22 setembro-outubro de 2000.

MICHAEL, A.; SALTER, B. Mobile marketing: Achiveving Competitive Advantage through wireless technology. Elsevier, 2006.

MMA - Mobile Marketing Association. Disponível em <http://www.mmaglobal.com>Acesso em 10 de Abril de 2009.

MOBILEPEDIA. <www.mobilepedia.com.br>. Acesso em 21 de Abril de 2009.

MORT, G. S.; DRENNAN J. Marketing m-services: Establishing a usage benefit typology related to mobile. Journal of Database Marketing \& Customer Strategy Management; jul. 2005; 12, 4; ABI/INFORM Global. p. 237.

MURPHY, J.; SCHARL, A.; DICKINGER, A. Diffudion and Success Factors of Mobile Marketing. Disponível em: web.biz.uwa.edu.au/staff/jmurphy/ECR2005.pdf>. Austrália: Elsevier, 2004. Acesso em 12 de Abril de 2009.

DO NASCIMENTO, S. C. M. O uso do mobile marketing como estratégia de fidelização de clientes: um estudo em empresas do setor de comércio e serviços em Natal - RN. Natal, 2007. Dissertação (Mestrado). UFRN.

REEDY, J.; SCHULLO, S.; ZIMMERMAN, K. Marketing eletrônico. Porto Alegre: Bookman, 2000.

ROESCH, S. M. A. Projetos de estágio e de pesquisa em administração: guia para estágios, trabalhos de conclusão, dissertações e estudos de caso. $3^{a}$ ed. São Paulo: Atlas, 2007.

SULTAN, F; ROHM, A. A marca na palma da mão. São Paulo. In: HSM Management. São Paulo, v. 2, n.55, p. 104, março-abril 2006.

PETERS, B. The future of wireless marketing. Disponível em: <www.caratinteractive.com/resources/artcles.html>. Acesso em 02 de Abril de 2009.

RAMUSKI, C. L. Comportamento do consumidor digital. In: LAS CASAS, A. L. (Org.). Marketing móvel: tendências e oportunidades no marketing eletrônico. São Paulo: Saint Paul Editora, 2009. P. 81-94 
RHEINGOLD, H. Tools for tought. 1985. Disponível em http://www.rheijgold.com/texts/tft/index.html. Acesso em 23 de Abril de 2009. .

ROMÁN, F.; GONZALES-MESONES, F.; MARINAS. Mobile marketing: a revolução multimídia. São Paulo: Thomson Learning , 2007.

SHETH, J. N; MITTAL, B.; NEWMAN, B. I. Comportamento do cliente: indo além do comportamento do consumidor. São Paulo: Atlas, 2001.

TAURION, C.. Internet móvel: tecnologias, aplicações e modelos. Editores Campus, Rio de Janeiro, 2002.

TECNOMUNDO. Disponível em <www.tecnomundo.com.br>. Acesso em 21 de Abril de 2009.

TELECO. Dados da telefonia móvel. Disponível em: <www.teleco.com.br>. Acesso em 30 de Marco de 2009.

TORRAS, P.; ALBUQUERQUE, T. Mobile Marketing: SMS como ferramenta de marketing. Rio de Janeiro: UniverCidade, 2005.

VERGARA, S. C. Projetos e relatórios de pesquisa em administração. $9^{a}$ ed. São Paulo: Atlas, 2007.

WEBINSIDER. Disponível em <www.webinsider.uol.com.br>. Acesso em 21 de Abril de 2009.

WIKIPEDIA. Disponível em <www.pt.wikipedia.org>. Acesso em 19 de Abril de 2009. 


\section{GLOSSÁRIO}

AMMB: Sigla para Associação de Marketing Móvel do Brasil. Entidade sem fins lucrativos que tem o objetivo de fomentar a tecnologia móvel como estratégia de comunicação e relacionamento utilizando aparelhos celulares e outros dispositivos móveis.

ANATEL: Agência Nacional de telecomunicações, órgão ligado ao Ministério das Telecomunicações, encarregado da regulamentação do mercado e dos serviços do setor.

BANDA LARGA: sistema que tem capacidade de transmissão de dados em alta velocidade.

CRM: customer relationship management ou gestão de relacionamento com o cliente. Diz respeito a todas as áreas de uma empresa que procuram administrar os contatos com os clientes existentes de modo a mantê-la fiel e torná-la mais lucrativa.

DOWNLOAD: recebimento de arquivo ou pacote de informações originário de outro equipamento, normalmente via internet. Transferência de arquivo de um computador para outro.

MMA: Mobile Marketing Association entidade de atuação mundial que tem como objetivo estimular o crescimento do mobile marketing.

RINGTONES: música ou som de campainha do celular.

SHORT CODE: são números curtos constituídos por quarto algarismos utilizados em campanhas de mobile marketing.

IP: internet protocol ou protocolo de internet é um protocolo usado em redes de dados como a internet, para transmitir informação de um ponto ao outro.

BLUETOOTH: tecnologia de transmissão de dados que possibilita a criação de redes de áreas pessoais permitindo aos usuários transmitir dados em uma velocidade alta a uma distância de 10 metros.

JAVA: linguagem de programação para internet e também celulares.

MMS - Multimedia Messaging Service ou Serviço de Mensagem Multimídia. Permite o envio de imagens, fotos, sons e textos em uma única mensagem para outro celular ou para um email. 
MOBILE MARKETING: caracteriza-se por ações de marketing que utiliza o canal móvel (celular).

OPT-IN, OPT-OUT: opção por parte do consumidor de participar ou não de programas ou campanhas que enviam mensagens promocionais de empresas.

PROSPECT: pessoa ou empresa que demonstra interesse em comprar um produto.

PULL: tipo de campanha de mobile marketing na qual o usuário solicita a informação ou produto, em vez de recebê-lo diretamente.

PUSH: tipo de campanha de mobile marketing na qual o usuário recebe diretamente a informação ou produto, sem ter que solicitá-lo a cada vez.

SMS: é a sigla em inglês para short message service, serviço de mensagens curtas. Através deste serviço você pode receber em seu telefone celular, diversos tipos de informação através de uma mensagem de texto.

SUSPECT: pessoa ou empresa considerada possível compradora de um produto ou serviço.

TARGET: mercardo-alvo e/ou público-alvo.

WAP: Wireless Application Protocol ou protocolo para aplicações sem fio. O WAP refere-se a uma série de protocolos ou especificações para desenvolver aplicações web para ambientes de rede móvel. 


\section{APÊNDICES}

\section{Questionário da pesquisa.}

\section{VOCÊ POSSUI UM CELULAR?}

( ) SIM

( ) NÃO (Favor entregar o questionário ao entrevistador)

\section{Senhor (a) Usuário de Celular!}

Sou aluno de Administração da Universidade de Brasília e estou realizando uma pesquisa com a finalidade de conhecer os seus interesses sobre o uso do celular. Esta pesquisa não tem valor comercial e somente intuitos acadêmicos. O questionário apresenta duas partes: sobre o uso do celular e sobre a utilização dele para marketing.

Este questionário não apresenta respostas certas ou erradas.

Muito obrigado pela sua atenção.

\section{PARTE 1: Uso do celular}

1- Há quanto tempo você é usuário de celular?

( ) 1 . Entre 1 e 6 meses

( ) 2. Entre 6 meses e 3 anos

( ) 3. Entre 3 anos e 5 anos

( ) 4. Há mais de 5 anos

2- Quantos aparelhos celulares você possui?

3 - Qual a marca do seu celular? (Se possuir mais de um aparelho, por favor, indique todas as marcas)?

4 - Qual operadora do seu celular? (Se possuir mais de uma por favor indique todas as operadoras)

5 - Com qual freqüência que você utiliza esses recursos do seu celular?

A - Mensagem de Texto (SMS):

( ) 1. Não utilizo este recurso

( ) 2. Menos de quatro vezes ao mês

( ) 3. Uma vez a cada semana

( ) 4. Entre 2 a 5 dias na semana

( ) 5 . Todos os dias 
( ) 6. Não tenho este recurso no meu celular

B - Internet Móvel:

( ) 1. Não utilizo este recurso

( ) 2. Menos de quatro vezes ao mês

( ) 3. Uma vez a cada semana

( ) 4. Entre 2 a 5 dias na semana

( ) 5 . Todos os dias

( ) 6. Não tenho este recurso no meu celular

C - Bluetooth (Esta ferramenta permite que exista troca de informações e arquivos sem necessidade de fio entre telefones celulares e entre outros equipamentos):

( ) 1. Não utilizo este recurso

( ) 2. Menos de quatro vezes ao mês

( ) 3. Uma vez a cada semana

( ) 4. Entre 2 a 5 dias na semana

( ) 5 . Todos os dias

( ) 6. Não tenho este recurso no meu celular

6 - Atribua uma nota de 1 a 10 (1 representa a nota mais baixa e 10 a mais alta) em relação ao que é interessante para você no momento de compra de um telefone celular:

( ) 1. Câmera Fotográfica

( ) 2. Conectividade

( ) 3. Bluetooth

( ) 4. MP3 Player

( ) 5. Internet Móvel (WAP)

( ) 6. Mensagem de texto (SMS)

( ) 7. Mensagem de foto/vídeo (MMS)

( ) 8. Fone de Ouvido

7 - Especificamente sobre a utilização do Bluetooth como ferramenta de conexão, como você classifica seu conhecimento sobre o seu uso dessa tecnologia? (Relembrando que o Bluetooth é uma ferramenta para transferência de arquivos e informações sem fio por aparelhos de tecnologia).

( ) 1. Não conheço esta ferramenta

( ) 2. Sei ativar o Bluetooth

( ) 3. Sei utilizar alguns recursos do Bluetooth

( ) 4. Sei fazer qualquer operação que o Bluetooth fornece

\section{PARTE 2: Receptividade ao Mobile Marketing}

O mobile marketing é toda publicidade, propaganda e mensagens enviadas pelos anunciantes através do celular. 
( ) 1. Sim, eu gostaria.

( ) 2. Talvez, e somente se pudesse escolher a quantidade de mensagens e assuntos que me interessem.

( ) 3. Talvez, e somente se tiver benefícios como descontos e prêmios do anunciante.

( ) 4. Não, eu não gostaria

2 - Favor assinalar em qual (ais) dos meios abaixo você prefere receber publicidade no celular (pode marcar mais de uma alternativa):

( ) 1. Mensagens de texto (SMS)

( ) 2. Mensagem de foto/vídeo (MMS)

( ) 3. Bluetooth

( ) 4. Internet Móvel (WAP)

( ) 5. Não tenho interesse em receber informações pelo celular

3 - Se você estivesse em um centro comercial, e fosse solicitado a você que ativasse o Bluetooth do seu celular para receber ofertas e serviços das lojas do local. Você:

( ) 1. Ativaria

( ) 2. Ativaria, desde que pudesse escolher quais tipos de informações e de quais anunciantes receberia as mensagens

( ) 3. Não ativaria

4 - Quanto a receber mensagens via Bluetooth, qual(ais) conteúdos abaixo você considera mais interessante (pode marcar mais de uma alternativa):

( ) 1. Informações sobre eventos e notícias.

( ) 2. Descontos e ofertas especiais

( ) 3. Imagens e vídeos

( ) 4. Músicas

( ) 5. Jogos multimídia

( ) 6. Promoções de produtos e serviços

( ) 8. Outros:

( ) 9. Não tenho interesse em nenhuma delas

5 - Na escala abaixo, favor marcar com um $X$ nos espaços delimitados aquilo que se aproxima com você, de acordo com a pergunta:

A - Como você se sente em receber informações pelo seu celular?

\begin{tabular}{|c|c|c|c|c|c|c|}
\hline 1. Confortável & 1. [ & 2. [ ] & 3. [ ] & 4. [ & 5. [ ] & Desconfortável \\
\hline 2. Animado & 1.[ & 2. & 3. [ & 4. [ & 5. [ & Desanimado \\
\hline 3. Desconfiado & 1. [ & 2. & 3. [ & 4. [ & 5. & Confiante \\
\hline 4. Desatualizado & 1. [ & 2. & 3. & 4. [ & 5.1 & Atualizado \\
\hline 5. Tradicional & 1. [ & 2. & 3. & 4. [ & 5. & Moderno \\
\hline 6. Desrespeitado & 1. [ & 2. [ & 3. [ & 4. [ & 5. [ & Respeitado \\
\hline
\end{tabular}


DADOS PESSOAIS:

1 - Idade:

2 - Sexo:

( ) 1. Masculino

( ) 2. Feminino

3 - Ocupação:

( ) 1. Estudante

( ) 2. Empregado

( ) 3. Servidor Público

( ) 4. Autônomo

( ) 5. Aposentado

4 - Grau de Escolaridade:

( ) 1. Fundamental completo

( ) 2. Superior incompleto

( ) 3. Superior completo

( ) 4. Pós-Graduação

5 - Renda familiar:

( ) 1. De $R \$ 400$ a $R \$ 1.500$

( ) 2. De $R \$ 1.501$ a $R \$ 3.000$

( ) 3. De $R \$ 3.001$ a $R \$ 5.000$

( ) 4. De $R \$ 5.001$ a $R \$ 8.000$

( ) 5 . Mais de $\mathrm{R} \$ 8.001$

6 - Estado (UF):

Críticas/Observações Gerais: 